\title{
Pyridyl thiosemicarbazide: synthesis, crystal structure, DFT/B3LYP, molecular docking studies and its biological investigations
}

\author{
Sraa Abu-Melha*
}

\begin{abstract}
$\mathrm{N}$-(pyridin-2-yl)hydrazinecarbothioamide has been synthesized and characterized by single-crystal X-ray and spectroscopic techniques. Furthermore, its geometry optimization, calculated vibrational frequencies, non-linear optical properties, electrostatic potential and average local ionization energy properties of molecular surface were being evaluated using Jaguar program in the Schrödinger's set on the basis of the density functional concept to pretend the molecular geometry and predict properties of molecule performed by the hybrid density functional routine B3LYP. Furthermore, the docking study of $\mathrm{N}$-(pyridin-2-yl)hydrazinecarbothioamide were applied against negative Escherichia coli bacterial and gram positive Staphylococcus aureus bacterial strains by Schrödinger suite program using XP glide protocol.

Keywords: N-(pyridin-2-yl)hydrazinecarbothioamide, Single-crystal X-ray, Spectral characterization, Molecular docking
\end{abstract}

\section{Introduction}

Compounds containing sulfur and nitrogen atoms appear to display antimicrobial activity; antiviral $[1,2]$, antifungal [3], antibacterial $[4,5]$, antitumor $[6,7]$, anticarcinogenic [8-10] and insulin mimetic properties [11]. The antitumor action could be credited to the hindrance of DNA production by the alteration in the reductive transformation of ribonucleotide to deoxyribonucleotide [8]. Thiosemicarbazides have also been utilized for spectrophotometric detection of metals [12-14], gadget applications with respect to media communications and optical storage $[15,16]$. Thiosemicarbazides are wellknown source in heterocyclic synthesis. They also exist in tautomeric $\mathrm{C}=\mathrm{S}$ (thione) and $(\mathrm{C}-\mathrm{S})$ thiol forms [17]. The presence of tautomeric forms as an equilibrium combination in solution is basic for their adaptable chelating behavior. From these application, we reported the isolation, X-ray crystal characterization, DFT computational

*Correspondence: sraa201318@gmail.com

Department of Chemistry, Faculty of Science of Girls, King Khaled

University, Abha, Saudi Arabia studies using B3LYP, molecular interaction docking studies and biological applications of $N$-(pyridin-2-yl)hydrazinecarbothioamide. This study aims to investigate the stability of different isomers either in solid state or solution and show the synergy between the experimental and theoretical data.

\section{Experimental}

\section{Equipment and materials}

All the substances were bought from different high quality sources and used as it is without any additional refining. The infra-red spectrum $\left(4000-400 \mathrm{~cm}^{-1}\right)$ by means of $\mathrm{KBr}$ discs was measured utilizing a Mattson 5000 FTIR spectrophotometer.

${ }^{1} \mathrm{H}$ NMR spectra was measured utilizing a JEOL $500 \mathrm{MHz}$ NMR spectrometer, in $\left(\right.$ DMSO- $\mathrm{d}_{6}$ ) at $25{ }^{\circ} \mathrm{C}$ using TMS as an internal standard. $\mathrm{D}_{2} \mathrm{O}$ solvent is applied to approve the assignment of the $\mathrm{NH}-$ and $\mathrm{SH}-$ protons. On the other hand, the theoretical calculation of the ${ }^{1} \mathrm{H}$ NMR for the different isomers of $\mathrm{N}$-(pyridin2-yl)hydrazinecarbothioamide was done using ACD/ SpecManager. 
An appropriate crystal for single-crystal X-ray study of the thiosemicarbazide has been selected and mounted onto thin glass fibers. An Enraf-Nonius 590 diffractometer having a Kappa CCD sensor utilizing graphite monochromated Mo-K $\alpha(\lambda=0.71073 \AA)$ was utilized for collection of the diffraction data of the colorless $\mathrm{X}$-ray single-crystal at normal temperature $\left(25^{\circ} \mathrm{C}\right)$ at the "National Research Center", Egypt. Reflection data have been recorded in the rotation mode using the $\phi$ and $\omega$ scan technique with $2 \theta_{\max }=27.49$ and 27.45. Without any critical peculiar dissipation, Friedel pairs have been combined. Changes in lit up volume were kept to a base and were considered by the multiscan interframe scaling $[18,19]$. The parameters of the unit cell were determined from least-squares refinement with $\theta$ in the range $0 \leq \theta \leq 30.11$ and $3.05 \leq \theta \leq 30.11$. The refinement was completed by full-framework slightest squares strategy on the positional and anisotropic temperature parameters of all non-hydrogen atoms on the basis of $F^{2}$ by means of CRYSTALS package [20]. The hydrogen atoms were set in figured positions and refined utilizing riding atoms with a typical settled isotropic thermal parameter [21].

\section{Synthesis of $N$-(pyridin-2-yl)hydrazinecarbothioamide}

$N$-(pyridin-2-yl)hydrazinecarbothioamide is synthesized utilizing Scheme 1. The obtained white precipitate filtered off, splashed using ethanol and desiccated over anhydrous $\mathrm{CaCl}_{2}$. (Yield 85\%, m.p. $193-195{ }^{\circ} \mathrm{C}$ ). Crystal suitable for X-ray measurements has been separated by recrystallization from acetonitrile.

\section{Molecular modeling}

Jaguar package [22] in the Schrödinger's complement [22] was utilized for structural geometry optimization. The density functional principle (DFT) to pretend chemical manners and predict properties of materials performed by the hybrid density functional technique B3LYP [23] implanted with a 6-311G $\mathrm{G}^{* * *}++$ basis set.

\section{Molecular docking \\ Protein preparation}

The three-dimensional complex structure of Escherichia coli (PDB ID: 1C14) and Staphylococcus aureus (PDB ID: 3BL6) were taken from the protein information store [24, 25]. The protein structures were readied utilizing the protein arrangement wizard software in the Schrödinger set [22] in which water molecules (radius $>5 \AA$ ) and trivial molecules found were expelled from the structure part, disulphide bonds were made and hydrogens were put onto the PDB constructions. Controlled impref minimization having the ordinary inputs was achieved on the structure with improved potentials for fluid reenactments (OPLS-2005) force field. The subsequent structures were utilized for receptor matrix age for docking.

\section{Ligand preparation}

The investigated compound were equipped utilizing the default procedure of the Ligprep program [22] in the Schrödinger's set. Glide program [22] in the Schrödinger's complement was utilized for molecular docking educations. It was docked to the marked protein by means of the glide dock XP practice without any utilization of implement post-docking minimization.

\section{Result and discussion}

${ }^{1} \mathrm{H}$ NMR of $\mathrm{N}$-(pyridin-2-yl)hydrazinecarbothioamide Experimental ${ }^{1} \mathrm{H}$ NMR $\left(500 \mathrm{MHz}\right.$, DMSO-d $\left.\mathrm{d}_{6}\right)$ ppm 5.23 (br. s., $2 \mathrm{H},\left[\mathrm{H}^{18}\right.$ and $\left.\left.\mathrm{H}^{19}\right]\right) 7.00-7.04\left(\mathrm{~m}, 1 \mathrm{H}, \mathrm{H}^{14}\right) 7.13(\mathrm{~d}$, $\left.\mathrm{J}=8.41 \mathrm{~Hz}, 1 \mathrm{H}, \mathrm{H}^{12}\right) 7.76\left(\mathrm{t}, \mathrm{J}=6.88 \mathrm{~Hz}, 1 \mathrm{H}, \mathrm{H}^{13}\right) 8.22$ (d, J = 5.36 Hz, $1 \mathrm{H}, \mathrm{H}^{15}$ ) 10.57 (s, $1 \mathrm{H}, \mathrm{H}^{16}$ ) 12.59 (br. s.,<smiles>Nc1ccccn1</smiles>

$$
+\mathrm{CS}_{2} \underset{\begin{array}{l}
\text { 1, 4- dioxane } \\
\text { stirring } 24 \mathrm{~h} .
\end{array}}{\stackrel{\text { Triethyl amine }}{\longrightarrow}}
$$
pyridin-2-amine<smiles>NNC(=S)Nc1ccccn1</smiles>
$\frac{\text { hydrazine hydrate }}{\text { in ethanol }}$

$N$-(pyridin-2-yl)hydrazinecarbothioamide

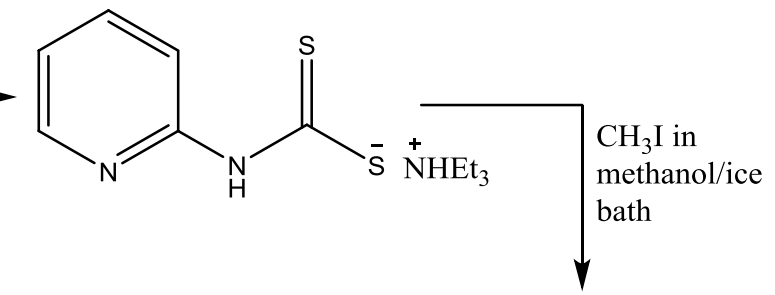<smiles>CSC(=S)Nc1ccccn1</smiles>

methyl pyridin-2-ylcarbamodithioate

Scheme 1 Scheme for synthesis of N-(pyridin-2-yl)hydrazinecarbothioamide 


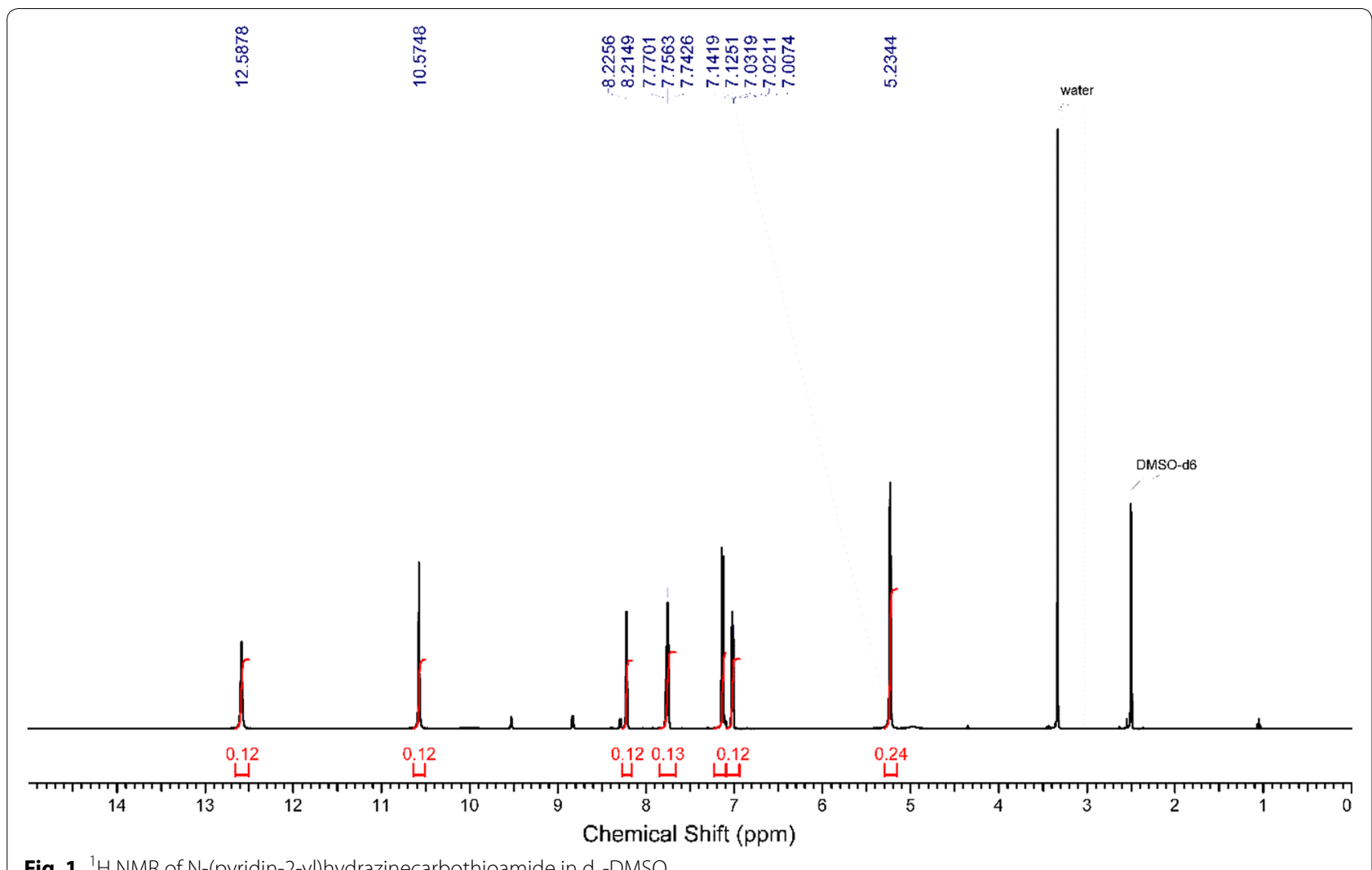

Fig. $1{ }^{1} \mathrm{H}$ NMR of $\mathrm{N}$-(pyridin-2-yl)hydrazinecarbothioamide in $\mathrm{d}_{6}$-DMSO

$1 \mathrm{H}, \mathrm{H}^{17}$ ) (Fig. 1). The disappearance of the signals of $\mathrm{H}^{16}$, $\mathrm{H}^{17}, \mathrm{H}^{18}$ and $\mathrm{H}^{19}$ on addition of $\mathrm{D}_{2} \mathrm{O}$ (Fig. 2), which suggests that they are easily exchangeable The presence of a signal at $12.59 \mathrm{ppm}$ attributable to $\mathrm{SH}$ proton confirming the presence of the $N$-(pyridin-2-yl)hydrazinecarbothioamide in the thiol form. Additional proof comes from the association of the experimental and theoretical data of the ${ }^{1} \mathrm{H}$ NMR for the different isomers of $N$-(pyridin2-yl)hydrazinecarbothioamide confirmed the presence of the thiosemicarbazide in the thiol form (isomer A) (Scheme 2) in DMSO solution as illustrated in Tables 1 and 2 in addition to Figs. 3, 4 and 5.

\section{Description of the crystal structure}

The processing data and crystallographic properties of $N$-(pyridin-2-yl)hydrazinecarbothioamide are summarized in Table 3 and Fig. 6 reveals the numbering pattern of $N$-(pyridin-2-yl)hydrazinecarbothioamide thiosemicarbazide. Table 4 illustrate the nominated bond lengths and angles. The ligand crystallizes in the $\mathrm{C} 2 / \mathrm{c}$ monoclinic space group with one molecule per asymmetric unit. It comprises of only one independent $N$-(pyridin-2-yl)hydrazinecarbothioamide molecule with no solvent molecules.

The least-squares planes as defined by the carbon atoms of the phenyl group besides the nitrogen atom of the pyridine ring and the atom directly bonded to it on the one hand and the carbon and nitrogen atoms of the chain-type substituent on the other hand enclose an angle of $9.51^{\circ}$. The $\mathrm{C}=\mathrm{S}$ bond length is found at $1.694 \AA$ which is intermediate between the usual values for a $\mathrm{S}\left(\right.$ ?)-C $\left(s p^{2}\right)$ single (1.75-1.78 $\AA$ ) and a double (1.59 $\AA$ ) bond and in good agreement with other reported thioketones [26]. The two $\mathrm{C}(=\mathrm{S})-\mathrm{N}$ bonds differ slightly in length with values of $1.322 \AA$ and $1.373 \AA$ with the longer bond established towards the nitrogenous atom bonded to the aromatic system. The N-N bond is measured at $1.417 \AA$ corresponds to a single bond. The most striking evidence for the single bond character of the $\mathrm{N}(11)-\mathrm{N}(9)$ bond is that the hydrogen atoms, placed in the positions calculated on the assumption that $\mathrm{N}(7)$ is trigonally hybridized in the mean molecular plane, lead to $\mathrm{H}$... $\mathrm{H}$ contact, with an adjacent molecule, which are greatly smaller $(1.22 \AA)$ than the value of the van der Waals radii $(2.40 \AA)$. In the crystal, intra- and intermolecular classical hydrogen bonds of the $\mathrm{N}-\mathrm{H}-\mathrm{N}$ type are apparent next to $\mathrm{C}-\mathrm{H}-\mathrm{S}$ contacts whose range falls below the sum of van-der-Waals radii (2.40 $\AA$ ) of the atoms participating in the construction stability [27]. The two molecules can be assumed to be practically coplanar and to be joined together in a dimer by the hydrogen bonds with the neighboring molecule. 

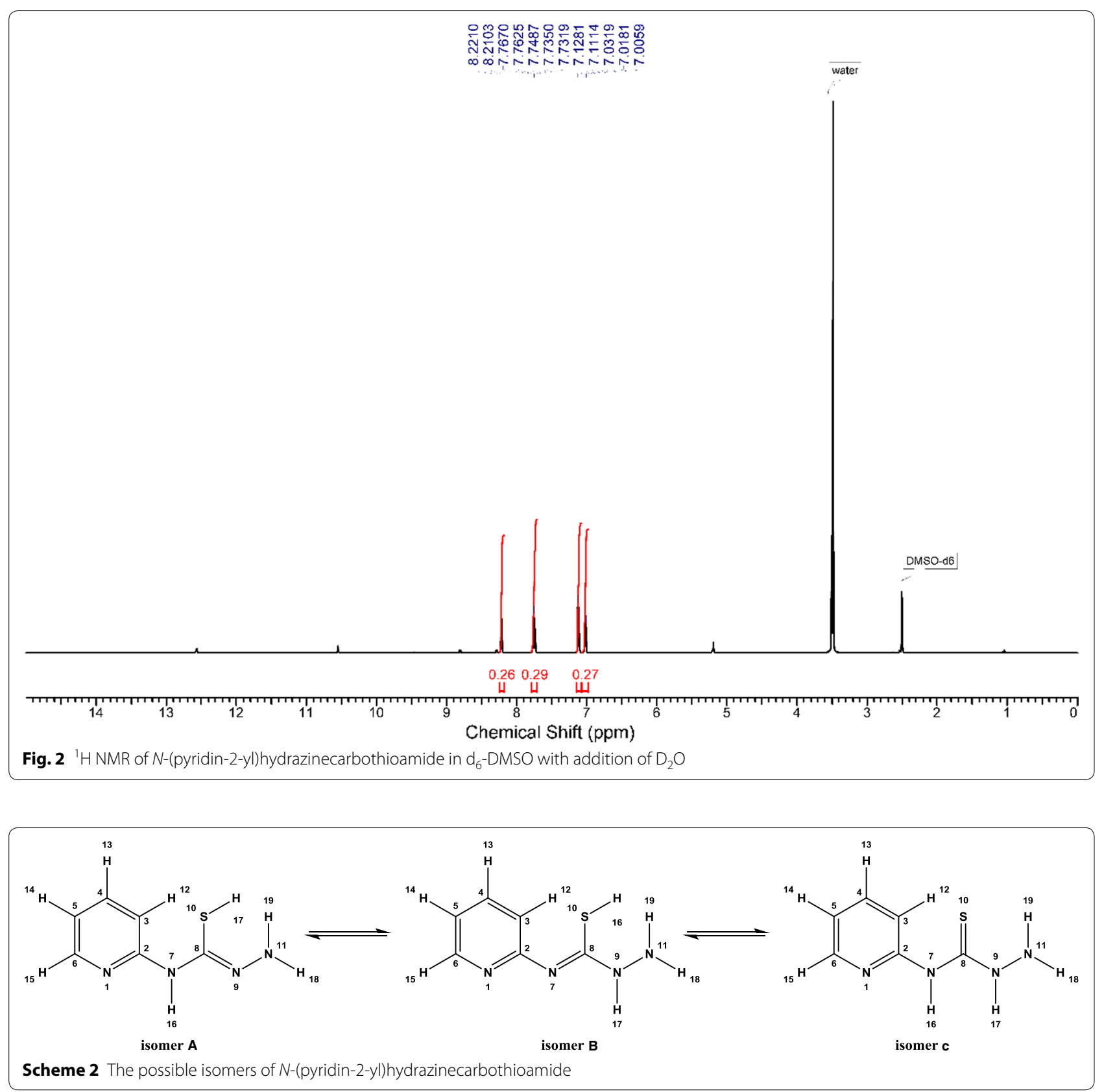

Table 1 Match factor, RMS of assignment, structure purity, reliability, $R^{2}$ of possible isomers related to experimental ${ }^{1}$ H NMR data

\begin{tabular}{lccc}
\hline Experimental ${ }^{\mathbf{1}} \mathbf{H}-\mathbf{N M R}$ & Isomer $\mathbf{A}$ & Isomer B & Isomer C \\
\hline Match factor & 0.94 & 0.44 & 0.19 \\
RMS of assignment (ppm) & 0.62 & 0.87 & 0.77 \\
Structure purity (\%) & 99.0 & 87.0 & 86.8 \\
Reliability (\%) & 87.0 & 74.7 & 68.5 \\
$\mathrm{R}^{2}$ & 0.97 & 0.88 & 0.89
\end{tabular}

As an issue of guideline, the packing figure of $N$-(pyridin-2-yl)hydrazinecarbothioamide construction (Fig. 7) is very straightforward. It consists of layers of ligand molecules with the same orientation (all the molecule pointing in the same direction), which are held together via hydrogen bonds as appeared in Fig. 8. There are $\pi-\pi$ stacking interactions with distances about 3.348$3.46 \AA$ between the molecules of each row, prompting heaps of stacked ligand molecules. The pyridine rings of the adjacent ligand molecule are not coplanar in the 
Table 2 Comparing of experimental shift (ppm) and calculated shift (ppm) possible isomers

\begin{tabular}{lcll}
\hline Experimental shift (ppm) & \multicolumn{3}{c}{ Calculated shift (ppm) } \\
\cline { 2 - 4 } & Isomer A & Isomer B & Isomer C \\
\hline 5.23 & 4.97 & 4.21 & 4.43 \\
7.02 & 6.99 & 8.34 & 7.34 \\
7.15 & 7.22 & 6.89 & 8.14 \\
7.75 & 7.71 & 7.43 & 7.82 \\
8.23 & 8.35 & 8.46 & 8.34 \\
10.58 & 9.38 & - & 10.16 \\
12.59 & 11.71 & 11.71 & - \\
\hline
\end{tabular}

solid state, which is probably due to stacking effects. In the crystal packing, offset $\pi-\pi$ stacking interactions have been observed between neighboring pyridine rings of two molecules in the head-to-tail arrangement forming similar dimeric packing structures, as displayed in Fig. 8. The centroid-centroid separations between the dimeric pairs are $3.586 \AA$.

\section{Molecular computational calculation} Geometry optimization using DFT

Structure 1 illustrates the optimized structure and numbering scheme of $N$-(pyridin-2-yl)hydrazinecarbothioamide. From the analysis of the estimated and measured data for the bond lengths and angles Table 4 one can observe the similarity between the estimated and measured data.

The calculated energy components and energies of both HOMO ( $\pi$ donor) and LUMO ( $\pi$ acceptor) Table 5 are main parameters in quantum chemical studies. Where, HOMO is the orbital that behaves as an electron giver, LUMO is the orbital that behave as the electron acceptor and these molecular orbitals are known as the frontier molecular orbitals (FMOs) Structure 1.

DFT technique illustrates the discernment of the molecular arrangements and expects the chemical reactivity. The energies of gas stage, FMOs ( $\left.E_{\mathrm{HOMO}}, E_{\mathrm{LUMO}}\right)$, electronegativity $(\chi)$, energy band gap that clarifies the inevitable charge exchange communication inside the particle inside the molecule, global hardness $(\eta)$, chemical potential $(\mu)$, global electrophilicity index $(\omega)$ and global softness $(S)[28,29]$ are recorded in Table 5.

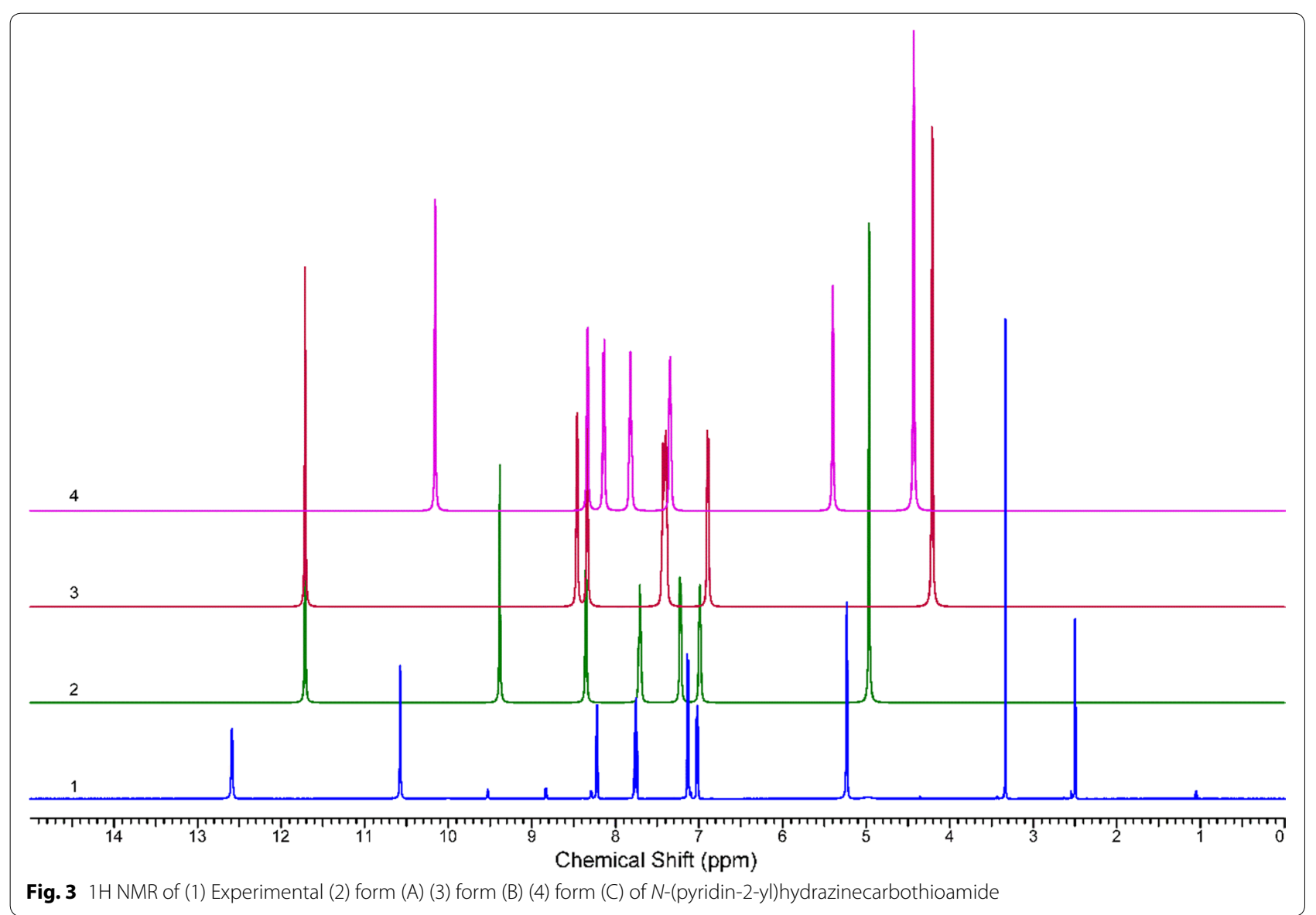



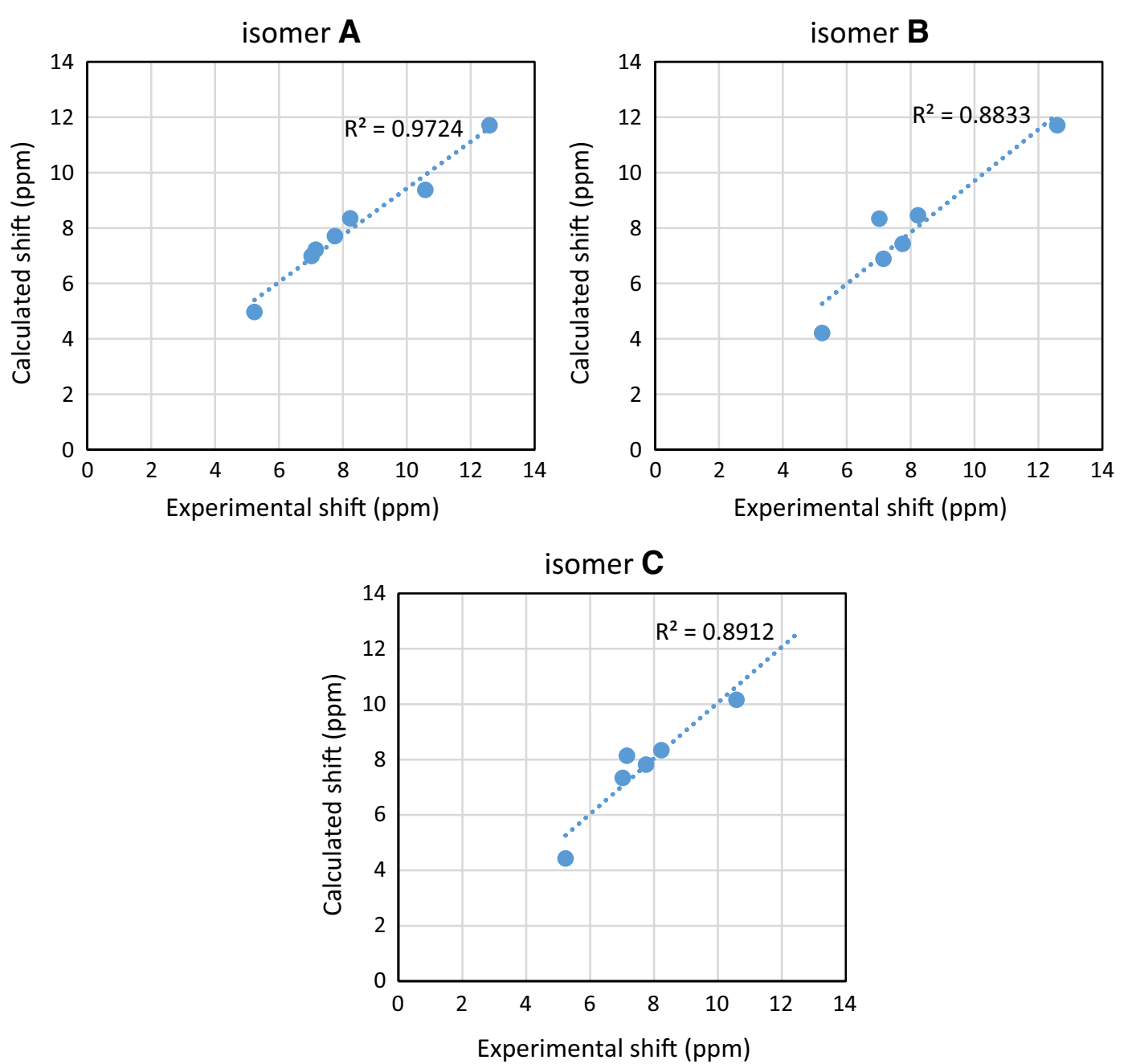

Fig. 4 The assignment of linear regression between experimental and calculated shift (ppm) of possible isomers

In numerous responses, the overlap amongst HOMO and LUMO orbitals assumed as an administering reason, where in compounds under examination; the orbitals with the higher molecular orbital coefficients can be considered as the fundamental destinations of the complexation. The energy gap $\left(E_{\mathrm{HOMO}}-E_{\mathrm{LUMO}}\right)$ is a noteworthy stability index simplify the description of both kinetic stability and chemical reactivity of the investigated moieties [30]. The energy gap of ligand is small showing that charge transfers easily in it and this influences the biological activity of the molecule, which agree with experimental data of antibacterial, and antifungal activities. Furthermore, the small quantity of energy difference can be assigned to the groups that enter into conjugation [31].

\section{Experimental IR and vibrational calculation}

In order to get the spectroscopic signature of ligands compounds, a frequency calculation analysis were carried out. The calculations were completed for free molecule in vacuum, while experiments were performed for solid sample (Table 6), so there are small differences between hypothetical and measured vibrational frequencies as illustrated in Fig. 9. The modes of vibrations are very complex because of the low symmetry of ligands. Particularly, in plane, out of plane and torsion vibrations have the greatest difficultly to allocate because of the involvement with the ring vibrations and with the substituent vibrations. However, there are some strong frequencies useful to characterize in the IR graph. The relationship that showed the similarities among the calculated and 

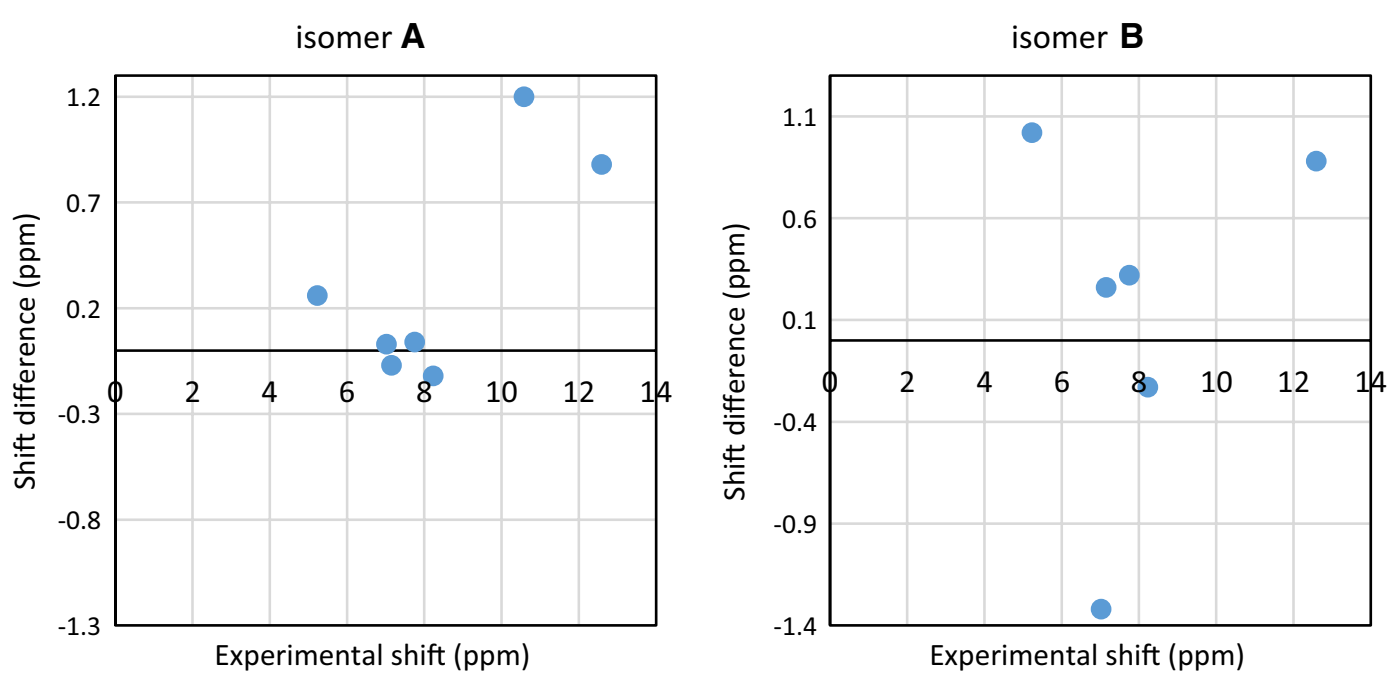

isomer $\mathbf{C}$

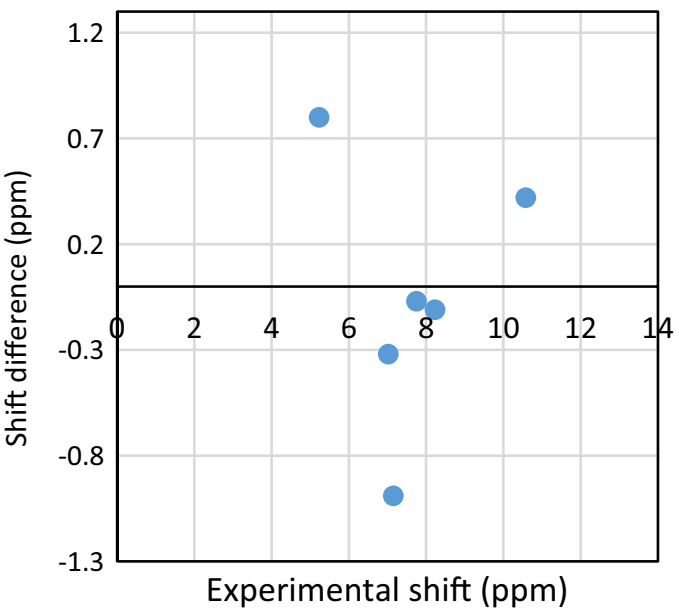

Fig. 5 Residual graphs of calculated shift (ppm) of possible isomers related to experimental shift (ppm)

measured data is illustrated in Fig. 10 which confirm the existence of the $\mathrm{N}$-(pyridin-2-yl)hydrazinecarbothioamide in the thione form (isomer $\mathrm{C}$ ). The relations between the calculated and experimental wavenumbers are linear for ligand and described by $v_{\text {cal }}=1.1111 v_{\operatorname{Exp}}-115.87$ with $\mathrm{R}^{2}=0.9963$.

As a glance of table and figures, one can conclude the following remarks:

i. The linear regression between the experimental and theoretical frequencies confirms the existence of the $N$-(pyridin-2-yl)hydrazinecarbothioamide in the thione form (isomer $\mathrm{C}$ ).

ii. The relations between the hypothetical and measured data is linear and described by equation $v_{\text {cal }}=1.1111$ $v_{\text {Exp }}-115.87$ with $R^{2}=0.9963$. iii. The two bands at 3240 and $3160 \mathrm{~cm}^{-1}$ were attributed to the stretching $(\mathrm{NH})^{7}$ and $(\mathrm{NH})^{9}$ groups, respectively [32].

iv. The bands observed at 1606, 1544 and $1243 \mathrm{~cm}^{-1}$ assigned to $v(C=N),(C=C)$ and $(C-N)$ stretching of pyridine rings, respectively [33]. Also the out of plane and in plane binding frequencies of $(\mathrm{C}=\mathrm{N})_{\mathrm{py}}$ appeared at 632 [34].

v. The thiosemicarbazide exhibited $v\left(-\mathrm{NH}_{2} \rightarrow=\mathrm{NH}\right)$ at 3025 and $3046 \mathrm{~cm}^{-1}$. While $v\left(-\mathrm{NH}_{2}\right)$ wagging appeared at $761 \mathrm{~cm}^{-1}$.

vi. A band at $1006 \mathrm{~cm}^{-1}$ corresponding to $v(\mathrm{~N}-\mathrm{N})$ [35] vii. The thioamide group $(\mathrm{HN}-\mathrm{C}=\mathrm{S})$ displayed four thioamide bands (I-IV) at $1474 \mathrm{~cm}^{-1}$ (I), $1337 \mathrm{~cm}^{-1}$ (II), $1143 \mathrm{~cm}^{-1}$ (III) and $893 \mathrm{~cm}^{-1}$ (IV) [36-39]. 
Table 3 Crystallographic data for $\mathbf{N}$-(pyridin-2-yl)hydrazinecarbothioamide

\begin{tabular}{|c|c|}
\hline & $\begin{array}{l}N \text {-(pyridin-2-yl)hydrazinecar- } \\
\text { bothioamide }\end{array}$ \\
\hline Formula & $\mathrm{C}_{6} \mathrm{H}_{8} \mathrm{~N}_{4} \mathrm{~S}$ \\
\hline Formula weight & 168.22 \\
\hline Temperature/K & 293 \\
\hline Crystal system & Monoclinic \\
\hline Space group & $\mathrm{C} 2 / \mathrm{c}$ \\
\hline \multicolumn{2}{|l|}{ Lattice parameters } \\
\hline$a / \AA$ & $15.5906(7)$ \\
\hline$b / \AA ̊$ & $10.1719(5)$ \\
\hline$c / \AA$ & $11.1763(6)$ \\
\hline$a^{\rho}$ & 90.00 \\
\hline$\beta \rho$ & $121.116(3)$ \\
\hline pe & 90.00 \\
\hline$V / \AA^{3}$ & $1517.39(13)$ \\
\hline Z & 8 \\
\hline$D_{\text {calc }} / \mathrm{g} / \mathrm{cm}^{3}$ & 1.473 \\
\hline$F_{000}$ & 704 \\
\hline$\mu_{\text {Mo-Ka }} \AA$ & 0.71073 \\
\hline Reflections collected & 7055 \\
\hline Independent reflections & 2200 \\
\hline Data/parameters/restrains & $2200 / 100 / 0$ \\
\hline Goodness of fit on $F^{2}$ & 1.041 \\
\hline Absorption coefficient $\mathrm{mm}^{-1}$ & 0.36 \\
\hline Final $R$ indices $(/>2.00 \sigma(I))$ & $R_{1}=0.0602, w R_{2}=0.1649$ \\
\hline$R$ indices (all data) & $R_{1}=0.1385, w R_{2}=0.1965$ \\
\hline $\begin{array}{l}\text { Maximum/minimum residual } \\
\text { electron density }\left(e . \AA^{-3}\right)\end{array}$ & $0.397 /-0.489$ \\
\hline
\end{tabular}

\section{Non-linear optical (NLO) properties}

The quantum chemistry based prediction of NLO possessions of $\mathrm{N}$-(pyridin-2-yl)hydrazinecarbothioamide has an essential part for the design of materials in communication technology, signal processing and optical interconnections [40]. The total static dipole moment $\mu$, the average linear polarizability $\bar{\alpha}$, the anisotropy of the polarizability $\Delta \alpha$, and the first hyper-polarizability $\beta$ can be calculated as reported by Sajan et al. [40]. Table 7 illustrates the ingredients of dipole moment, polarizability and the average first hyper-polarizability of $\mathrm{N}$-(pyridin2-yl)hydrazinecarbothioamide framework.

The estimated data were changed into Debye $\AA^{3}$ and electrostatic units (e.s.u.) utilizing the well-known conversion relations (for $\mu$ : 1 a.u. $=2.5416$ Debye; for $\alpha$ : 1 a.u. $=0.14818 \AA^{3}$; for $\beta$ : 1 a.u. $=8.641 \times 10^{-33}$ e.s.u.) [41]. Urea is utilizes as an acute parameter for comparison studies because it has a decent NLO activity $(\mu=1.3732$ Debye, $\bar{\alpha}=3.8312 \AA^{3}$ and $\beta=3.7289 \times 10^{-31} \mathrm{~cm}^{5} /$ e.s.u. $)$. Furthermore $\quad N$-(pyridin-2-yl)hydrazinecarbothioamide have parameters $\mu=4.4481$ Debye, $\bar{\alpha}=18.9817 \AA^{3}$, $\Delta \alpha=44.3551 \AA^{3}$, and $\beta=2.1727 \times 10^{-30} \mathrm{~cm}^{5} /$ e.s.u.

The first hyper-polarizability of $N$-(pyridin-2-yl)hydrazinecarbothioamide is greater than that of urea 5.82 times, respectively. According to the magnitude of $\beta$, the $N$-(pyridin-2-yl)hydrazinecarbothioamide under study may be have a potential applicant in the improvement of NLO materials due to they have a worthy non-linear property.

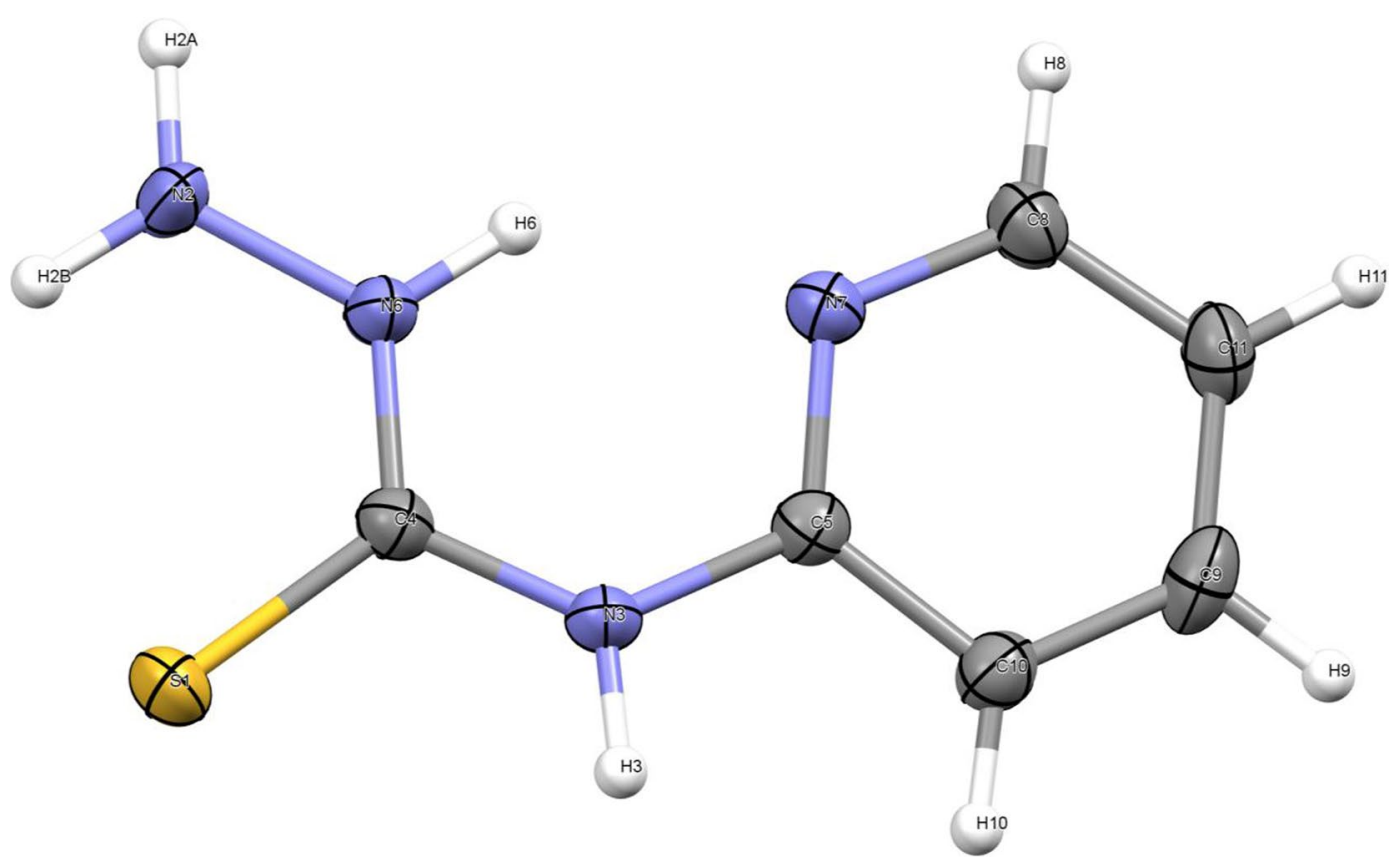

Fig. 6 Numbering scheme and atomic displacement ellipsoids drawn at 30\% probability level for N-(pyridin-2-yl)hydrazinecarbothioamide 
Table 4 Calculated and experimental bond lengths and angles of $\mathbf{N}$-(pyridin-2-yl)hydrazinecarbothioamide

\begin{tabular}{|c|c|c|c|c|c|}
\hline Bond length $(\AA)$ & Experimental & Calculated & Bond angle $\left(^{\circ}\right)$ & Experimental & Calculated \\
\hline $\mathrm{N}(11)-\mathrm{H}(19)$ & 0.960 & 1.017 & $H(19)-N(11)-H(18)$ & 119.98 & 106.253 \\
\hline $\mathrm{N}(11)-\mathrm{H}(18)$ & 0.961 & 1.020 & $\mathrm{H}(19)-\mathrm{N}(11)-\mathrm{N}(9)$ & 120.95 & 108.166 \\
\hline $\mathrm{N}(9)-\mathrm{H}(17)$ & 0.959 & 1.011 & $\mathrm{H}(18)-\mathrm{N}(11)-\mathrm{N}(9)$ & 119.07 & 108.041 \\
\hline$N(9)-N(11)$ & 0.960 & 1.403 & $H(17)-N(9)-N(11)$ & 118.54 & 113.006 \\
\hline$C(8)-S(10)$ & 1.694 & 1.659 & $\mathrm{H}(17)-\mathrm{N}(9)-\mathrm{C}(8)$ & 119.25 & 117.287 \\
\hline$C(8)-N(9)$ & 1.322 & 1.375 & $N(11)-N(9)-C(8)$ & 121.93 & 123.165 \\
\hline $\mathrm{N}(7)-\mathrm{H}(16)$ & 0.960 & 1.011 & $S(10)-C(8)-N(9)$ & 123.68 & 123.344 \\
\hline$N(7)-C(8)$ & 1.373 & 1.386 & $S(10)-C(8)-N(7)$ & 118.41 & 125.997 \\
\hline $\mathrm{C}(6)-\mathrm{H}(15)$ & 0.960 & 1.086 & $N(9)-C(8)-N(7)$ & 117.86 & 110.598 \\
\hline $\mathrm{C}(5)-\mathrm{H}(14)$ & 0.961 & 1.083 & $H(16)-N(7)-C(8)$ & 120.06 & 115.499 \\
\hline$C(5)-C(6)$ & 1.373 & 1.392 & $\mathrm{H}(16)-\mathrm{N}(7)-\mathrm{C}(2)$ & 100.36 & 115.529 \\
\hline $\mathrm{C}(4)-\mathrm{H}(13)$ & 0.960 & 1.084 & $C(8)-N(7)-C(2)$ & 129.58 & 127.311 \\
\hline$C(4)-C(5)$ & 1.378 & 1.393 & $H(15)-C(6)-C(5)$ & 116.44 & 120.511 \\
\hline $\mathrm{C}(3)-\mathrm{H}(12)$ & 0.960 & 1.084 & $H(15)-C(6)-N(1)$ & 119.79 & 115.736 \\
\hline$C(3)-C(4)$ & 1.368 & 1.388 & $C(5)-C(6)-N(1)$ & 123.76 & 123.746 \\
\hline$C(2)-N(7)$ & 1.393 & 1.411 & $H(14)-C(5)-C(6)$ & 119.30 & 120.536 \\
\hline$C(2)-C(3)$ & 1.404 & 1.401 & $H(14)-C(5)-C(4)$ & 122.56 & 121.507 \\
\hline$N(1)-C(6)$ & 1.339 & 1.334 & $C(6)-C(5)-C(4)$ & 118.12 & 117.957 \\
\hline \multirow[t]{10}{*}{$N(1)-C(2)$} & 1.333 & 1.329 & $H(13)-C(4)-C(5)$ & 120.68 & 120.811 \\
\hline & & & $H(13)-C(4)-C(3)$ & 119.40 & 120.179 \\
\hline & & & $C(5)-C(4)-C(3)$ & 119.92 & 119.003 \\
\hline & & & $H(12)-C(3)-C(4)$ & 122.34 & 121.139 \\
\hline & & & $H(12)-C(3)-C(2)$ & 119.57 & 120.609 \\
\hline & & & $C(4)-C(3)-C(2)$ & 118.09 & 118.243 \\
\hline & & & $N(7)-C(2)-C(3)$ & 118.27 & 118.948 \\
\hline & & & $N(7)-C(2)-N(1)$ & 119.09 & 117.693 \\
\hline & & & $C(3)-C(2)-N(1)$ & 122.65 & 123.293 \\
\hline & & & $C(6)-N(1)-C(2)$ & 117.45 & 117.728 \\
\hline
\end{tabular}

\section{Electrostatic potential (ESP) and average local ionization energy (ALIE) properties on molecular surface}

Electrostatic potential $V(r)$ and average local ionization energy $\bar{I}(r)$ of molecule have confirmed to be active guides to its reactive behavior [42].

Electrostatic potential $\mathrm{V}(\mathrm{r})$ and average local ionization energy $\bar{I}(r)$ of all frameworks were shown in Structures 2 and 3, respectively. Also, estimated molecular surface data showed in Table 8. This table include the following parameters:

i. The data of the most positive and most negative $V_{S, \max }$ and $V_{S, \min }$.

ii. Overall surface potential value $\bar{V}_{S}$, its positive and negative averages $\bar{V}_{s}^{+}$and $\bar{V}_{s}^{-}$. iii. The internal charge transfer (local polarity) $\Pi$, which is deduced as a meter for the internal charge separation and it is present even in molecules with zero dipole moment because of the symmetry.

iv. The variances, $\sigma_{+}^{2}, \sigma_{-}^{2}$ and $\sigma_{\text {tot }}^{2}$ which reflect the strengths and variabilities of the positive, negative and overall surface potentials [43].

v. An electrostatic balance parameter $v=0.25$, that illustrate the extent of the equilibrium amongst the positive and negative potentials; when $\sigma_{+}^{2}=\sigma_{-}^{2}$

vi. The most positive and most negative $\bar{I}_{S, \text { max }}^{+}$and $\bar{I}_{S, \text { min }}$ and the average over the surface of the local ionization energy $\bar{I}_{S, \text { ave }}$. 

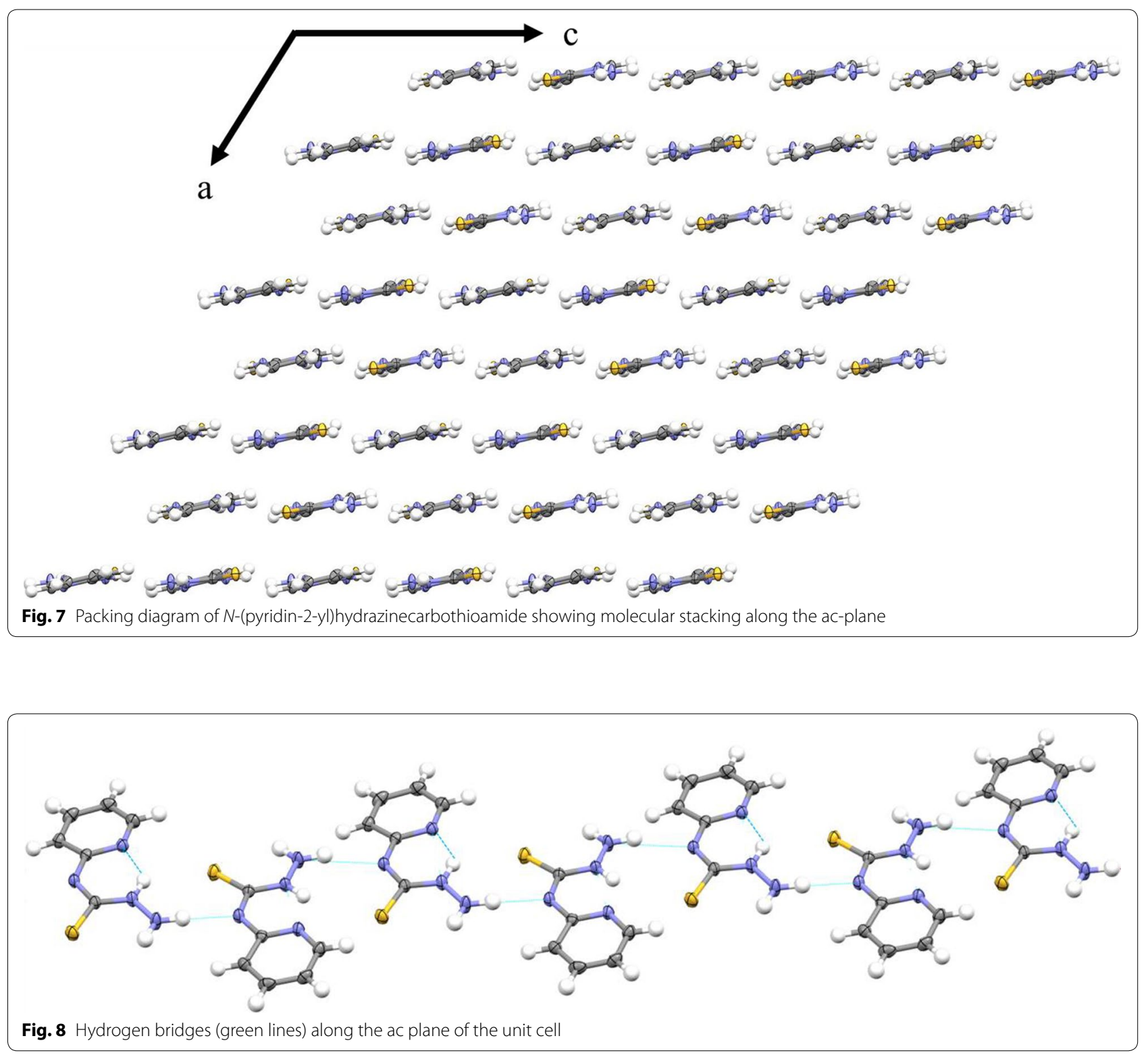

From Table 8 we notice that $N$-(pyridin-2-yl)hydrazinecarbothioamide has the internal charge separation, $\Pi=15.37 \mathrm{kcal} \mathrm{mol}^{-1}$, may be due to it was structurally quite symmetric.

In Structures 2 and 3 is displayed the $V_{S}(r)$ and $\bar{I}_{S}(r)$ on surfaces of $N$-(pyridin-2-yl)hydrazinecarbothioamide. These structures show the locations of the various most positive and most negative $V_{S}(r), V_{S, \max }$ and $V_{S \text {, min }}$, and the highest and lowest $\bar{I}_{S}(r), \bar{I}_{S \text {, max }}$ and $\bar{I}_{S, \text { min }}$. There are often several local maxima and minima of each property on a studied molecular surface. The most negative electrostatic potential on $\mathrm{N}$-(pyridin-2-yl)hydrazinecarbothioamide surface is related to the nitrogen (N1) of pyridine ring, $V_{S, \min }=-41.62 \mathrm{kcal} \mathrm{mol}^{-1}$, followed by weaker value $-38.6 \mathrm{kcal} \mathrm{mol}^{-1}$ on the sulfur (S10). Thus, $V_{S}(r)$ would wrongly predict electrophilic attack to occur preferentially at the nitrogen. In contrast, the lowest values of $\bar{I}_{S}(r)$ placed on the (S10), with $\bar{I}_{S, \text { min }}=159.79 \mathrm{kcal} \mathrm{mol}^{-1}$; also, there is an $\bar{I}_{S, \text { min }}$ by the hydrogen (H18), but it is much higher, $165.39 \mathrm{kcal} \mathrm{mol}^{-1}$. 

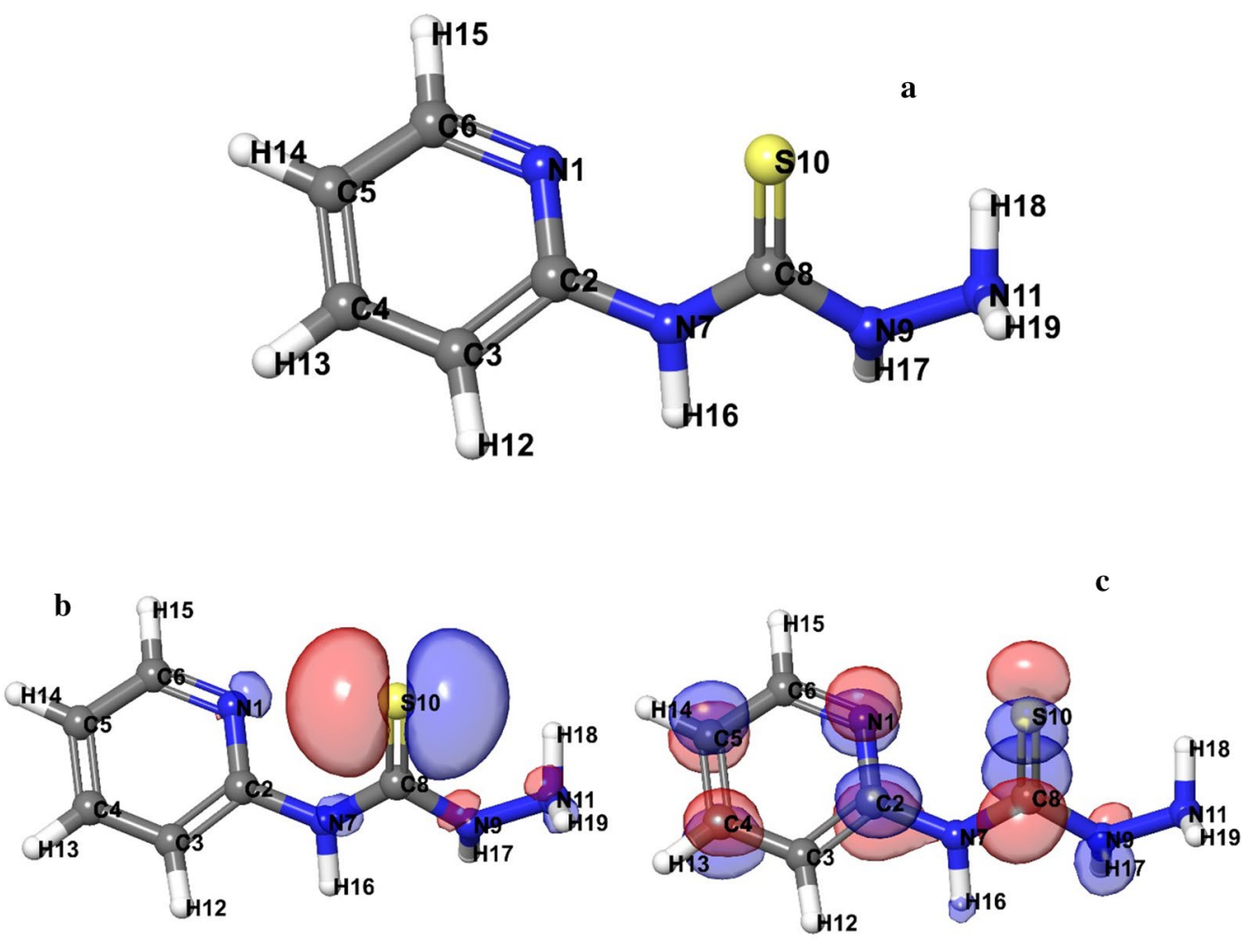

$$
\mathrm{E}_{\mathrm{H}}=-5.956(\mathrm{eV})
$$$$
\mathrm{E}_{\mathrm{L}}=-1.375(\mathrm{eV})
$$

Structure 1 Geometry optimization using DFT method of ligands a N-(pyridin-2-yl)hydrazinecarbothioamide, b HOMO and c LUMO

Table 5 Calculated energy components, $E_{\text {HOMO, }} E_{\text {LUMO }}$ energy band gap $\left(E_{H}-E_{L}\right)$, chemical potential $(\mu)$, electronegativity $(\mathrm{X})$, global hardness $(\boldsymbol{\eta})$, global softness (S) and global electrophilicity index $(\omega)$ for $\mathbf{N}$-(pyridin-2-yl) hydrazinecarbothioamide

\begin{tabular}{lrlr}
\hline Energy components & Kcal/mol & $\begin{array}{l}\text { Energetic } \\
\text { parameters }\end{array}$ \\
\hline Nuclear repulsion & $4.14 \times 10^{5}$ & $E_{\mathrm{H}}(\mathrm{eV})$ & -5.956 \\
Total one-electron terms & $-1.55 \times 10^{6}$ & $E_{\mathrm{L}}(\mathrm{eV})$ & -1.375 \\
Electron-nuclear & $-2.08 \times 10^{6}$ & $\left(E_{\mathrm{H}}-E_{\mathrm{L}}\right)(\mathrm{eV})$ & -4.580 \\
Kinetic & $5.32 \times 10^{5}$ & $X(\mathrm{eV})$ & 3.665 \\
Total two-electron terms & $6.04 \times 10^{5}$ & $\mu(\mathrm{eV})$ & -3.665 \\
Coulomb & $6.60 \times 10^{5}$ & $\eta(\mathrm{eV})$ & 2.290 \\
Exchange and correlation & $-5.58 \times 10^{4}$ & $S\left(\mathrm{eV}{ }^{-1}\right)$ & 1.145 \\
Electronic energy & $-9.48 \times 10^{5}$ & $\omega(\mathrm{eV})$ & 2.933 \\
Gas phase energy & $-5.34 \times 10^{5}$ & $\sigma(\mathrm{eV})$ & 0.436 \\
\hline
\end{tabular}

Table 6 Expermintal and theoretical wavenumber $\left(\mathrm{cm}^{-1}\right)$ of $\mathbf{N}$-(pyridin-2-yl)hydrazinecarbothioamide

\begin{tabular}{lcc}
\hline $\begin{array}{l}\text { Function } \\
\text { group }\end{array}$ & $\begin{array}{l}\text { Experimental } \\
\text { wavenumber }\left(\mathbf{c m}^{\mathbf{- 1}}\right)\end{array}$ & $\begin{array}{l}\text { Theoretical } \\
\text { wavenumber }\left(\mathbf{c m}^{\mathbf{- 1}}\right)\end{array}$ \\
\hline $\mathrm{v}\left(\mathrm{NH}{ }_{2}\right)$ & 3025,3046 & 3155,3185 \\
$\mathrm{v}(\mathrm{NH})^{7}$ & 3241 & 3589 \\
$\mathrm{v}(\mathrm{NH})^{9}$ & 3160 & 3515 \\
$\mathrm{v}(\mathrm{C}=\mathrm{N})_{\text {py }}$ & 1606 & 1631 \\
$\mathrm{v}(\mathrm{C}=\mathrm{C})_{\text {py }}$ & 1544 & 1530 \\
$\mathrm{v}(\mathrm{C}-\mathrm{N})_{\text {py }}$ & 1243 & 1270 \\
$\delta(\mathrm{C}=\mathrm{N})_{\text {py }}$ & 632 & 650 \\
$\mathrm{v}(\mathrm{NH})_{\text {wag }}$ & 761 & 755 \\
$\mathrm{v}(\mathrm{N}-\mathrm{N})$ & 1006 & 971 \\
Thioamide (I) & 1474 & 1475 \\
Thioamide (II) & 1337 & 1330 \\
Thioamide (III) & 1143 & 1175 \\
Thioamide (IV) & 893 & 890 \\
$\delta(\mathrm{C}-\mathrm{S})$ & 701 & 710 \\
\end{tabular}




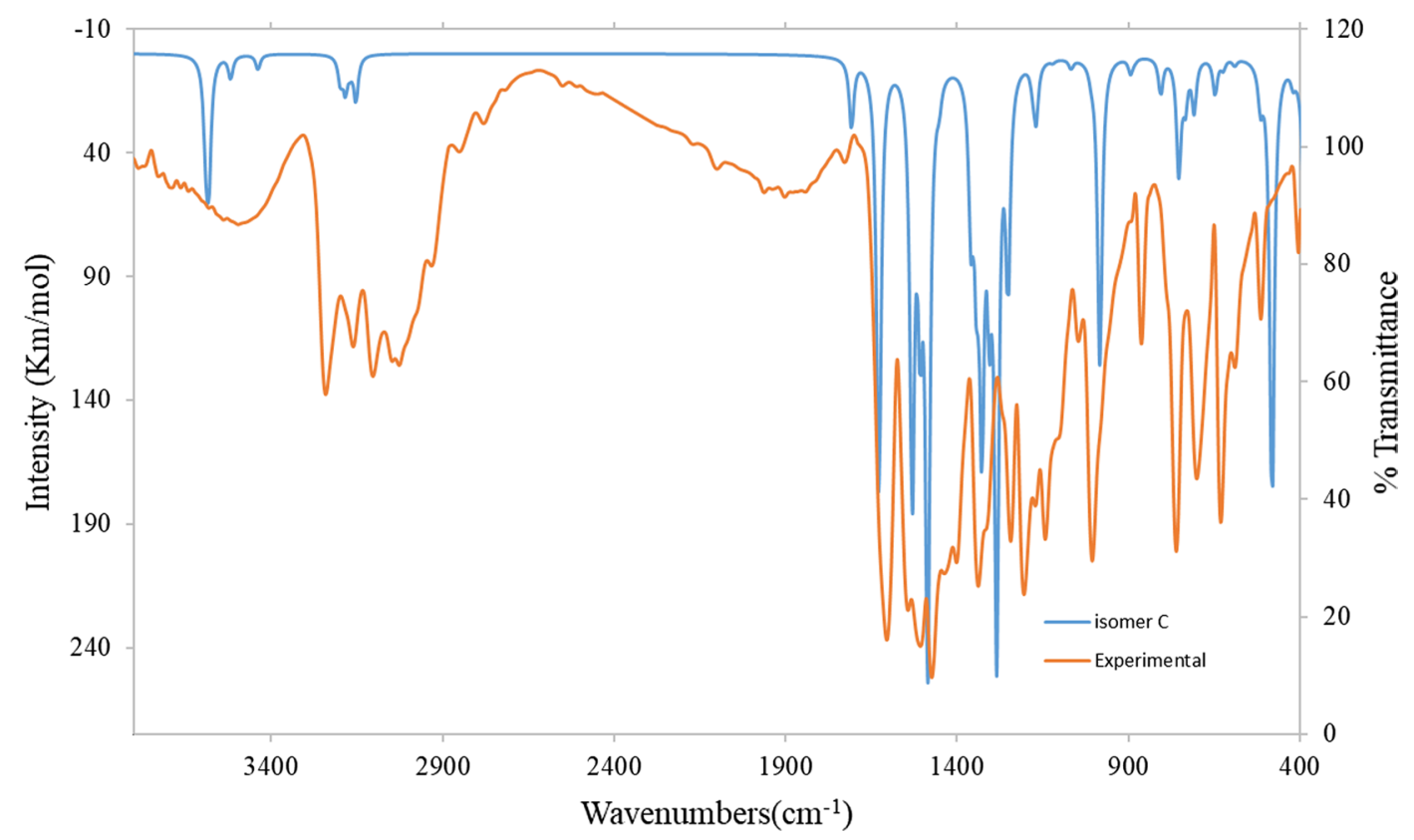

Fig. 9 Comparison of experimental and theoretical IR spectra of $\mathrm{N}$-(pyridin-2-yl)hydrazinecarbothioamide

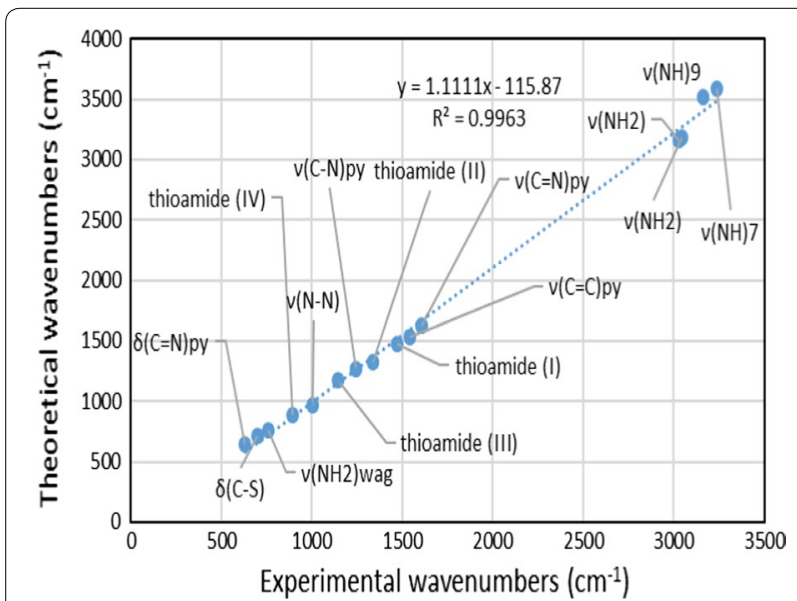

Fig. 10 The linear regression between the experimental and theoretical frequencies of $\mathrm{N}$-(pyridin-2-yl)hydrazinecarbothioamide

Thus, $\bar{I}_{S}(r)$ shows the most reactive, least-tightly-bound electrons to be at the (S10), properly indicating these sites to be most susceptible to electrophiles. On the other hand, the very strongly positive electrostatic potential of the hydrogen $(\mathrm{H} 16), V_{S, \max }=48.98 \mathrm{kcal} \mathrm{mol}^{-1}$, and the
Table 7 Calculated dipole moments (D), polarizability and the first hyperpolarizability components (a.u.) for ligand compounds

\begin{tabular}{llll}
\hline Dipole moment (a.u.) & \multicolumn{3}{c}{$\begin{array}{l}\text { First hyperpolarizabil- } \\
\text { ity (a.u.) }\end{array}$} \\
\hline$\mu_{x}$ & -0.25195 & $\beta_{x x x}$ & $-3.91 \times 10^{2}$ \\
$\mu_{y}$ & 1.55977 & $\beta_{y y y}$ & -74.10 \\
$\mu_{z}$ & 0.75273 & $\beta_{z z z}$ & -36.80 \\
$\mu$ & 1.75013 & $\beta_{x y y}$ & $1.03 \times 10^{2}$ \\
Polarizability (a.u.) & & $\beta_{x z z}$ & 42.60 \\
$a_{x x}$ & 168.596 & $\beta_{y x x}$ & -10.60 \\
$a_{x y}$ & -16.288 & $\beta_{y z z}$ & 49.30 \\
$a_{x z}$ & -7.067 & $\beta_{z x x}$ & -33.00 \\
$a_{y y}$ & 122.347 & $\beta_{z y y}$ & 31.70 \\
$a_{y z}$ & 13.479 & $\beta_{x y z}$ & 38.00 \\
$a_{z z}$ & 93.355 & $\Sigma \beta_{x}$ & $-2.46 \times 10^{2}$ \\
$\bar{\alpha}$ & 128.099 & $\Sigma \beta_{y}$ & -35.40 \\
$\Delta a$ & 299.3229 & $\Sigma \beta_{z}$ & -38.10 \\
& & $\beta$ & 251.4374 \\
\hline
\end{tabular}

$V_{S, \text { min }}=-41.62 \mathrm{kcal} \mathrm{mol}^{-1}$ of the nitrogen (N1) indicate their tendencies for noncovalent hydrogen bonding, as a donor and an acceptor, respectively. 


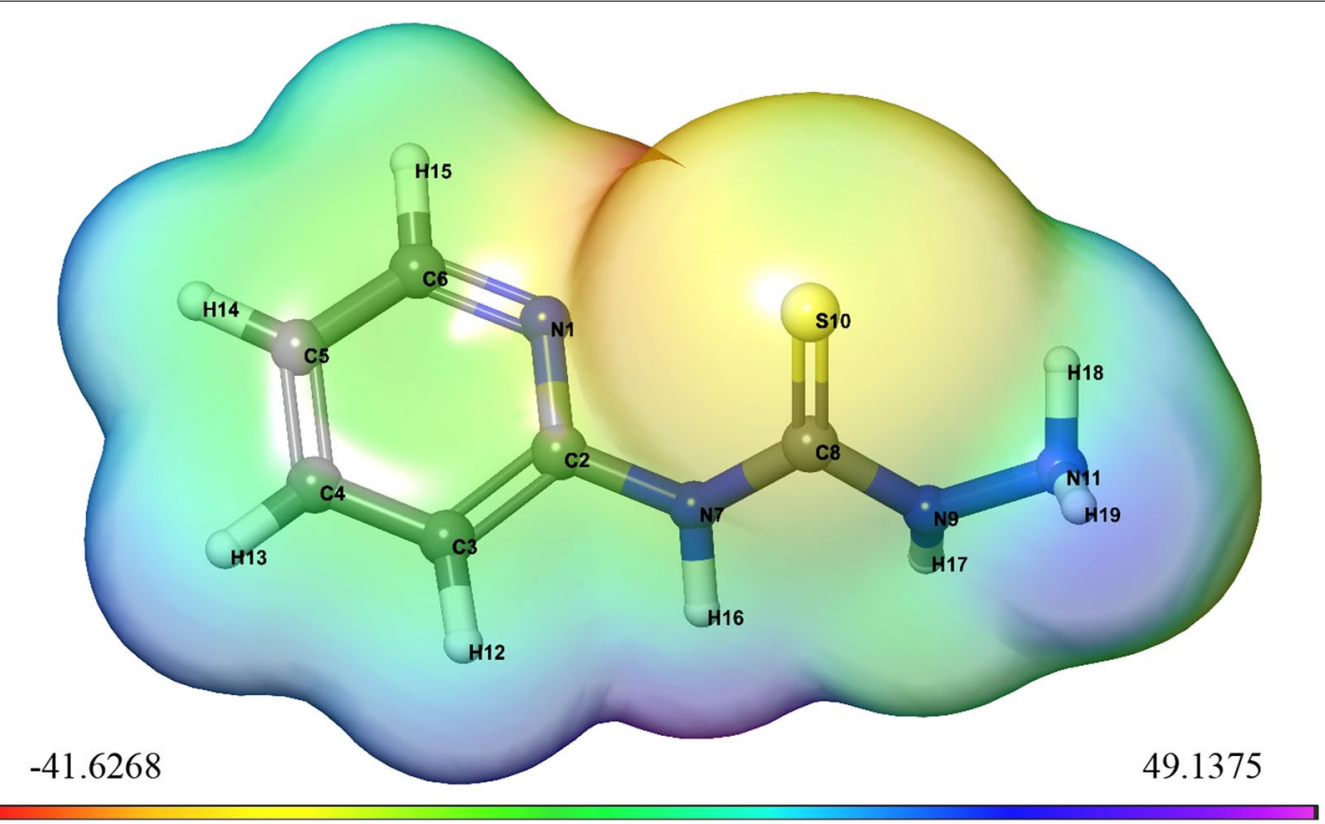

Structure 2 Surface structure of ESP using DFT method for N-(pyridin-2-yl)hydrazinecarbothioamide

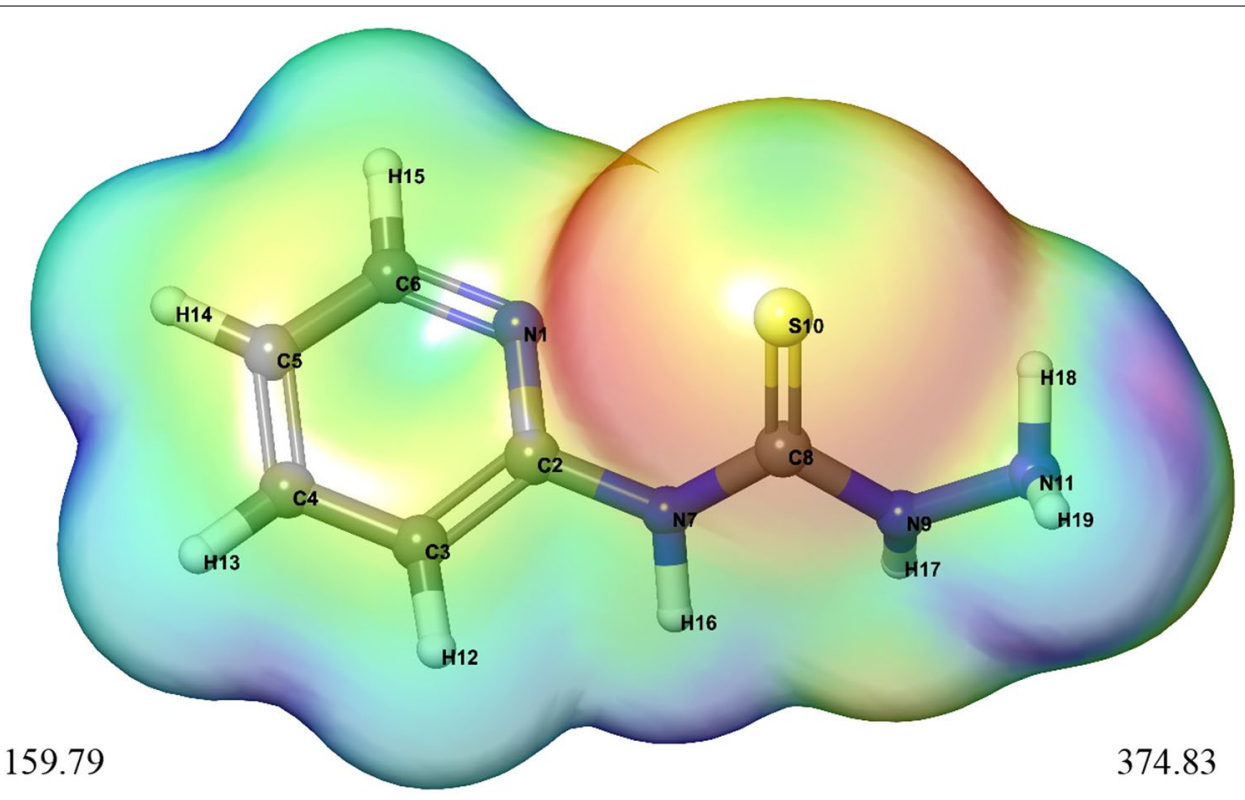

Structure 3 Surface structure of ALIE using DFT method for N-(pyridin-2-yl)hydrazinecarbothioamide 
Table 8 Computed molecular surface properties (ESP) and (ALIE) of compound

\begin{tabular}{lrlrlr}
\hline$V_{s, \text { min }}$ & -41.62 & $\sigma_{+}^{2}$ & 116.01 & $\bar{l}_{s, \text { min }}$ & 159.79 \\
$V_{s, \text { max }}$ & 48.98 & $\sigma_{-}^{2}$ & 106.73 & $\bar{l}_{s, \max }$ & 374.80 \\
$\bar{V}_{s}$ & 1.10 & $\sigma_{\text {tot }}^{2}$ & 222.74 & $\bar{l}$ & 252.47 \\
$\bar{V}_{s}^{+}$ & 15.03 & $V$ & 0.25 & $\bar{l}_{s, \text { ave }}$ & 39.74 \\
$\bar{V}_{s}^{-}$ & -15.96 & $\sqcap$ & 15.37 & & \\
\hline
\end{tabular}

Units: $V_{s, \text { min }}, V_{s, \text { max }} \bar{V}_{s}, \bar{V}_{s}^{+}, \bar{V}_{s}^{-}, \Pi, \bar{l}_{s, \text { min }}, \bar{I}_{s, \text { max }} \bar{l}_{s}$ and $\bar{l}_{s, \text { ave }}$ are in $\mathrm{kcal} / \mathrm{mol} ; \sigma_{+,}^{2}, \sigma_{-}^{2}$ $\sigma_{\text {tot }}^{2}$ are in $(\mathrm{kcal} / \mathrm{mol})^{2} ; \mathrm{v}$ is unitless

\section{Molecular docking}

The molecular interaction of $N$-(pyridin-2-yl)hydrazinecarbothioamide for inhibition against $E$. coli and $S$. aureus are represented in Structures 4, 5, 6 and 7 shows exchanges with the active site residues with dock score -4.523 and $-5.265 \mathrm{kcal} / \mathrm{mol}$ for both $E$. coli and $S$. aureus, respectively. The affinity of $N$-(pyridin-2-yl) hydrazinecarbothioamide against $E$. coli is resulting from two hydrogen bonds interaction $\left(\mathrm{NH}_{2} \rightarrow\right.$ TYR156 and $(\mathrm{NH})^{7} \rightarrow$ ALA196). While, the interaction with $S$. aureus resulting from the molecular hydrogen bonds interaction $\left(\mathrm{NH}_{2} \rightarrow\right.$ SER75 and $(\mathrm{NH})^{9} \rightarrow \mathrm{H}_{2} \mathrm{O} \rightarrow$ GLU11).

\section{Conclusion}

Novel thiosemicarbazide; $N$-(pyridin-2-yl)hydrazinecarbothioamide has been isolated and described utilizing single-crystal X-ray and ${ }^{1} \mathrm{HNMR}$. Additionally, its geometry optimization, calculated vibrational frequencies, non-linear optical properties, electrostatic potential and average local ionization energy properties of molecular surface were being assessed by means of Jaguar program

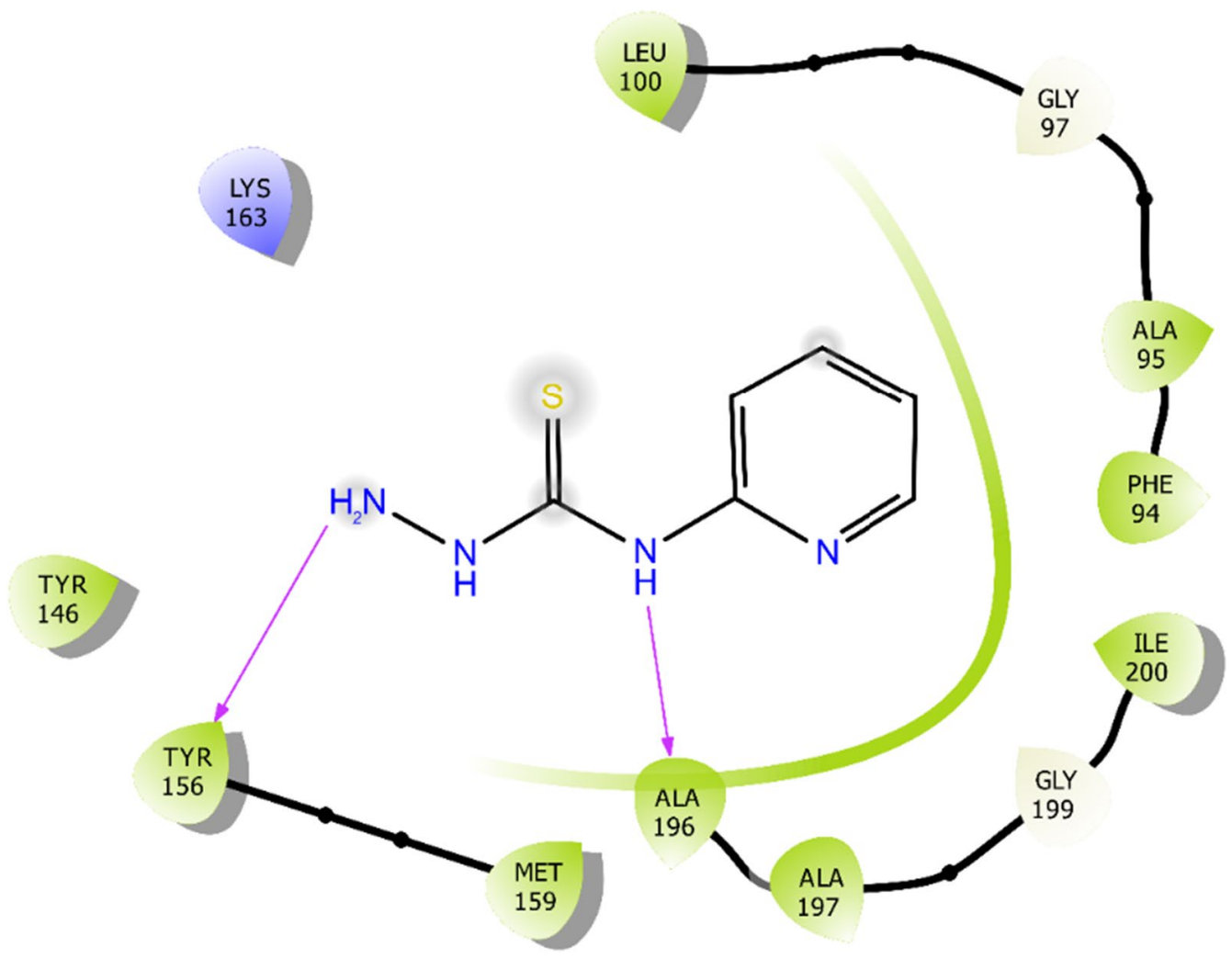

Structure 4 2D molecular interaction of $N$-(pyridin-2-yl)hydrazinecarbothioamide for inhibitor to $E$. coli 


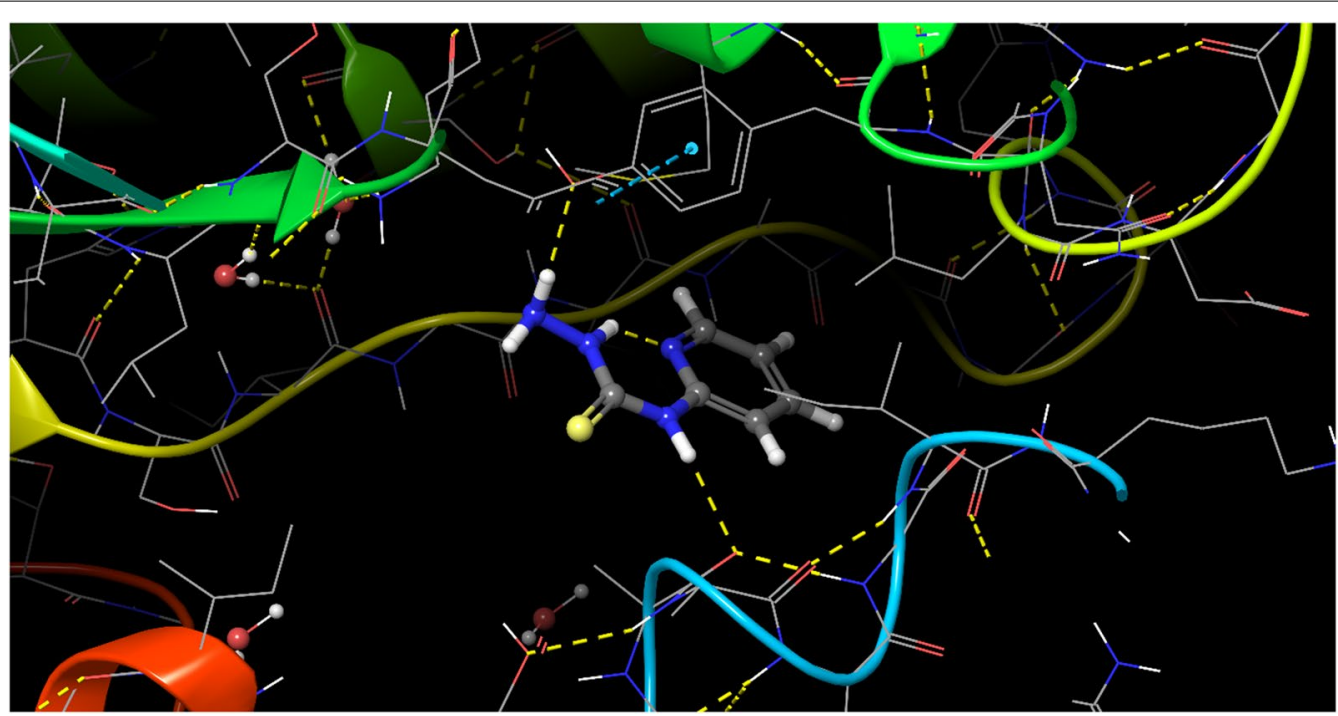

Structure 5 3D molecular interaction of $\mathrm{N}$-(pyridin-2-yl)hydrazinecarbothioamide for inhibitor to E. coli

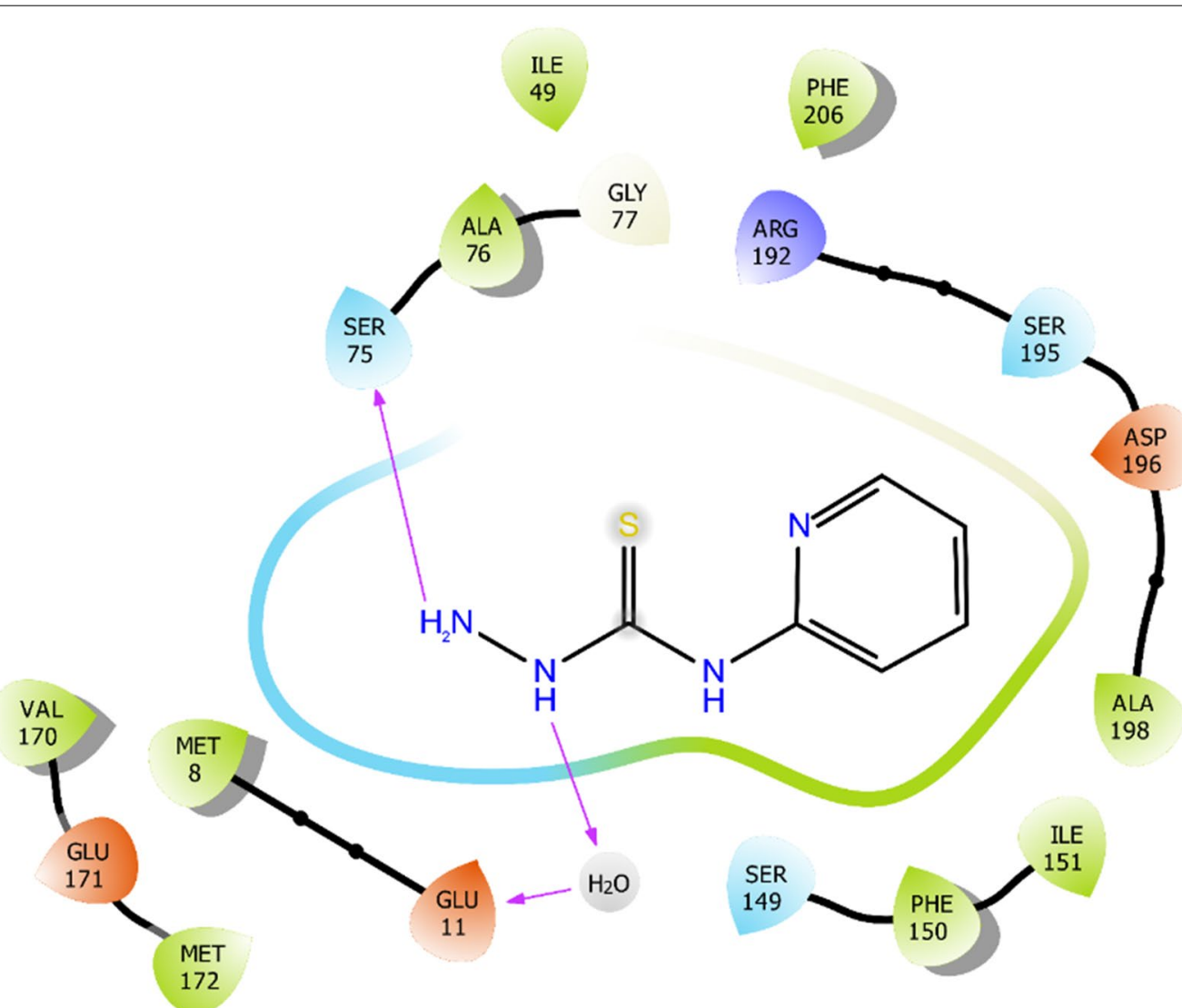

Structure 6 2D molecular interaction of $N$-(pyridin-2-yl)hydrazinecarbothioamide for inhibitor to S. aureus 


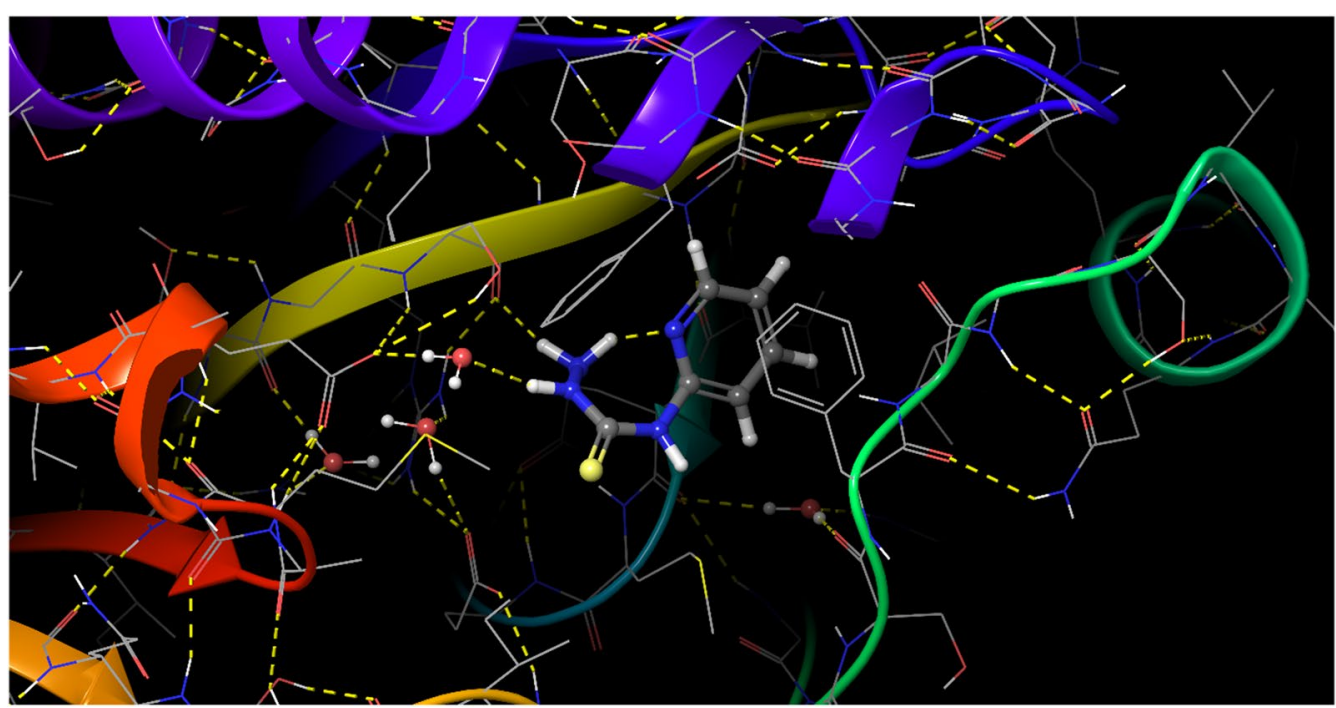

Structure 7 3D molecular interaction of $\mathrm{N}$-(pyridin-2-yl)hydrazinecarbothioamide for inhibitor to S. aureus

in the Schrödinger's set on the basis of the density functional concept (DFT) to pretend the molecular geometry and predict properties of molecule performed by the hybrid density functional routine B3LYP. Finally, the docking study of $\mathrm{N}$-(pyridin-2-yl)hydrazinecarbothioamide were applied against negative $E$. coli bacterial and gram positive $S$. aureus bacterial strains by Schrödinger suite program using XP glide protocol.

\section{Authors' contributions}

The author read and approved the final manuscript.

\section{Acknowledgements}

Not applicable.

\section{Competing interests}

The author declare that they have no competing interests.

\section{Availability of data and materials}

Not applicable.

\section{Ethics approval and consent to participate}

Not applicable.

\section{Funding}

Not applicable.

\section{Publisher's Note}

Springer Nature remains neutral with regard to jurisdictional claims in published maps and institutional affiliations.

Received: 16 February 2018 Accepted: 20 September 2018 Published online: 29 September 2018

\section{References}

1. Siegle HE (1973) Metal ions in biological systems. Dekker, New York

2. Eichharm GLE (1973) Inorganic biochemistry. Elsevier, New York

3. Koutlemani M, Mavros P, Zouboulis A, Matis K (1994) Recovery of $\mathrm{CO}^{2+}$ ions from aqueous solutions by froth flotation. Sep Sci Technol 29(7):867-886

4. Quenelle DC, Keith KA, Kern ER (2006) In vitro and in vivo evaluation of isatin- $\beta$-thiosemicarbazone and marboran against vaccinia and cowpox virus infections. Antiviral Res 71(1):24-30

5. Teitz Y, Barko N, Abmmoff M, Ronen D (1994) Relationships between structure and antiretroviral activity of thiosemicarbazone derivatives. Chemotherapy 40(3): 195-200

6. Rodríguez-Argüelles MC, López-Silva EC, Sanmartín J, Pelagatti P, Zani F (2005) Copper complexes of imidazole-2-, pyrrole-2-and indol-3-carbaldehyde thiosemicarbazones: inhibitory activity against fungi and bacteria. J Inorg Biochem 99(11):2231-2239

7. Bacchi A, Carcelli M, Pelagatti P, Pelizzi G, Rodriguez-Arguelles M, Rogolino D, Solinas C, Zani DF (2005) Antimicrobial and mutagenic properties of organotin (IV) complexes with isatin and $\mathrm{N}$-alkylisatin bisthiocarbonohydrazones. J Inorg Biochem 99(2):397-408

8. Cukurovali A, Yilmaz I, Gur S, Kazaz C (2006) Synthesis, antibacterial and antifungal activity of some new thiazolylhydrazone derivatives containing 3-substituted cyclobutane ring. Eur J Med Chem 41(2):201-207

9. Murugkar A, Unnikrishnan B, Padhye S, Bhonde R, Teat S, Triantafillou E, Sinn E (1999) Hormone anchored metal complexes. 1. Synthesis, structure, spectroscopy and in vitro antitumor activity of testosterone acetate thiosemicarbazone and its metal complexes. Met-Based Drugs 6(3):177-182

10. Hu W-X, Zhou W, Xia C-N, Wen X (2006) Synthesis and anticancer activity of thiosemicarbazones. Bioorg Med Chem Lett 16(8):2213-2218

11. Afrasiabi Z, Sinn E, Padhye S, Dutta S, Padhye S, Newton C, Anson CE, Powell AK (2003) Transition metal complexes of phenanthrenequinone thiosemicarbazone as potential anticancer agents: synthesis, structure, spectroscopy, electrochemistry and in vitro anticancer activity against human breast cancer cell-line, T47D. J Inorg Biochem 95(4):306-314

12. Bal T, Atasever B, Solakoğlu Z, Erdem-Kuruca S, Ülküseven B (2007) Synthesis, characterisation and cytotoxic properties of the N1, N4-diarylidene-S-methyl-thiosemicarbazone chelates with Fe(III) and Ni (II). Eur J Med Chem 42(2):161-167

13. West DX, Padhye SB, Sonawane PB (1991) In: Structural and physical correlations in the biological properties of transition metal heterocyclic thiosemicarbazone and S-alkyldithiocarbazate complexes. Springer, Berlin, pp 1-50 
14. West DX, Liberta AE, Padhye SB, Chikate RC, Sonawane PB, Kumbhar AS, Yerande RG (1993) Thiosemicarbazone complexes of copper (II): structural and biological studies. Coord Chem Rev 123(1-2):49-71

15. Ferrari MB, Fava GG, Leporati E, Pelosi G, Rossi R, Tarasconi P, Albertini R, Bonati A, Lunghi P, Pinelli S (1998) Synthesis, characterisation and biological activity of three copper (II) complexes with a modified nitrogenous base: 5-formyluracil thiosemicarbazone. J Inorg Biochem 70(2):145-154

16. Sonawane P, Chikate R, Kumbhar A, Padhye S, Doedens RJ (1994) Inequivalent coordination of thiosemicarbazone ligands in cobalt (III) and chromium (III) complexes. Polyhedron 13(3):395-401

17. Hall IH, Chen S, Barnes BJ, West DX (1999) The hypolipidemic activity of heterocyclic thiosemicarbazones, thioureas and their metal complexes in Sprague dawley male rats. Met-Based Drugs 6(3):143-147

18. GoËrbitz CH (1999) What is the best crystal size for collection of X-ray data? Refinement of the structure of glycyl-L-serine based on data from a very large crystal. Acta Crystallogr Sect B Struct Sci 55(6):1090-1098

19. Otwinowski Z, Minor W (1997) Processing of X-ray diffraction data collected in oscillation mode. In: Methods in enzymology, Vol 276, Elsevier, pp 307-326

20. Betteridge PW, Carruthers JR, Prout K, Watkin DJ (2003) CRYSTALS version 12: software for guided crystal structure analysis. J Appl Crystallogr $36: 1487$

21. Cooper RI, Thompson AL, Watkin DJ (2010) CRYSTALS enhancements: dealing with hydrogen atoms in refinement. J Appl Crystallogr 43:1100-1107

22. Schrödinger Suite 2016-1

23. Becke AD (1993) Density-functional thermochemistry. III. The role of exact exchange. J Chem Phys 98(7):5648-5652

24. Siu KKW, Lee JE, Smith GD, Horvatin-Mrakovcic C, Howell PL (2008) Structure of Staphylococcus aureus 5'-methylthioadenosine/S-adenosylhomocysteine nucleosidase. Acta Crystallogr Sect F Struct Biol Cryst Commun 64(5):343-350

25. Sogabe S, Masubuchi M, Sakata K, Fukami TA, Morikami K, Shiratori Y, Ebiike H, Kawasaki K, Aoki Y, Shimma N, D’Arcy A, Winkler FK, Banner DW, Ohtsuka T (2002) Crystal structures of Candida albicans N-myristoyltransferase with two distinct inhibitors. Chem Biol 9(10):1119-1128

26. Allen FH (2002) The Cambridge Structural Database: a quarter of a million crystal structures and rising. Acta Crystallogr Sect B Struct Sci 58(3):380-388

27. Bondi A (1964) van der Waals volumes and radii. J Phys Chem 68(3):441-451

28. Pearson RG (1989) Absolute electronegativity and hardness: applications to organic chemistry. J Org Chem 54(6):1423-1430

29. Padmanabhan J, Parthasarathi R, Subramanian V, Chattaraj P (2007) Electrophilicity-based charge transfer descriptor. J Phys Chem A 111(7):1358-1361

30. Govindarajan M, Periandy S, Carthigayen K (2012) FT-IR and FT-Raman spectra, thermo dynamical behavior, HOMO and LUMO, UV, NLO properties, computed frequency estimation analysis and electronic structure calculations on a-bromotoluene. Spectrochim Acta Part A 97:411-422
31. Abu El-Reash GM, El-Gammal O, Ghazy S, Radwan A (2013) Characterization and biological studies on $\mathrm{Co}(\mathrm{II}), \mathrm{Ni}(\mathrm{II})$ and $\mathrm{Cu}(\mathrm{II})$ complexes of carbohydrazones ending by pyridyl ring. Spectrochim Acta A Mol Biomol Spectrosc 104:26-34

32. El-Ayaan U, Kenawy I, El-Reash YA (2007) Synthesis, thermal and spectral studies of first-row transition metal complexes with Girard-T reagentbased ligand. J Mol Struct 871(1):14-23

33. Rakha TH, El-Gammal OA, Metwally HM, Abu El-Reash GM (2014) Synthesis, characterization, DFT and biological studies of (Z)- $N^{\prime}$-(2-oxoindolin-3ylidene) picolinohydrazide and its $\mathrm{Co}(\mathrm{II}), \mathrm{Ni}(\mathrm{II})$ and $\mathrm{Cu}(\mathrm{II})$ complexes. J Mol Struct 1062:96-109

34. Garg BS, Kurup MP, Jain SK, Bhoon YK (1988) Manganese (II) complexes of substituted thio-and selenosemicarbazones of 2-acetylpyridine: Esr, magnetic and electronic spectral studies. Transit Met Chem 13(2):92-95

35. El-Gammal OA, El-Reash GMA, El-Gamil MM (2014) Structural, spectral, pH-metric and biological studies on mercury (II), cadmium (II) and binuclear zinc (II) complexes of NS donor thiosemicarbazide ligand. Spectrochim Acta Part A 123:59-70

36. Desseyn H, Van der Veken B, Herman M (1978) The characteristic pattern of thioamides in infrared and Raman spectra. Appl Spectrosc 32(1):101-105

37. Ketcham KA, Garcia I, Swearingen JK, El-Sawaf AK, Bermejo E, Castineiras A, West DX (2002) Spectral studies and X-ray crystal structures of three nickel (II) complexes of 2-pyridineformamide 3-piperidylthiosemicarbazone. Polyhedron 21(8):859-865

38. Corban GJ, Hadjikakou SK, Hadjiliadis N, Kubicki M, Tiekink ERT, Butler IS, Drougas E, Kosmas AM (2005) Synthesis, structural characterization, and computational studies of novel diiodine adducts with the heterocyclic thioamides $\mathrm{N}$-methylbenzothiazole-2-thione and benzimidazole2-thione: implications with the mechanism of action of antithyroid drugs. Inorg Chem 44(23):8617-8627

39. Gaber M, Fayed TA, El-Gamil MM, Abu El-Reash GM (2018) Structural, thermogravimetric, B3LYP and biological studies on some heterocyclic thiosemicarbazide copper (II) complexes and evaluation of their molecular docking. J Mol Struct 1151:56-72

40. Sajan D, Joe H, Jayakumar V, Zaleski J (2006) Structural and electronic contributions to hyperpolarizability in methyl $p$-hydroxy benzoate. J Mol Struct 785(1):43-53

41. Joshi BD (2016) Chemical reactivity, dipole moment and first hyperpolarizability of aristolochic acid I. J Inst Sci Technol 21(1):1-9

42. Bulat FA, Toro-Labbé A, Brinck T, Murray JS, Politzer P (2010) Quantitative analysis of molecular surfaces: areas, volumes, electrostatic potentials and average local ionization energies. J Mol Model 16(11):1679-1691

43. Murray JS, Brinck T, Lane P, Paulsen K, Politzer P (1994) Statisticallybased interaction indices derived from molecular surface electrostatic potentials: a general interaction properties function (GIPF). J Mol Struct THEOCHEM 307:55-64

\section{Submit your manuscript to a SpringerOpen ${ }^{\odot}$ journal and benefit from:}

- Convenient online submission

- Rigorous peer review

- Open access: articles freely available online

- High visibility within the field

Retaining the copyright to your article

Submit your next manuscript at springeropen.com 